\title{
INNOCENT BYSTANDERS? MONETARY POLICY AND INEQUALITY IN THE
} U.S.

\author{
Olivier Coibion \\ Yuriy Gorodnichenko \\ Lorenz Kueng \\ John Silvia \\ Working Paper 18170 \\ http://www.nber.org/papers/w18170 \\ NATIONAL BUREAU OF ECONOMIC RESEARCH \\ 1050 Massachusetts Avenue \\ Cambridge, MA 02138 \\ June 2012
}

The authors acknowledge the financial support of the Global Interdependence Center and are grateful to Stefania Albanesi, Pierre Jaillet, Aysegul Sahin and seminar participants at the New York Fed and Global Interdependence Center Conference for comments. We thank Peter Ireland for sharing his data. The views in the paper are those of the authors and do not necessarily represent those of Wells Fargo or the National Bureau of Economic Research.

At least one co-author has disclosed a financial relationship of potential relevance for this research. Further information is available online at http://www.nber.org/papers/w18170.ack

NBER working papers are circulated for discussion and comment purposes. They have not been peerreviewed or been subject to the review by the NBER Board of Directors that accompanies official NBER publications.

(C) 2012 by Olivier Coibion, Yuriy Gorodnichenko, Lorenz Kueng, and John Silvia. All rights reserved. Short sections of text, not to exceed two paragraphs, may be quoted without explicit permission provided that full credit, including $(\mathcal{C}$ notice, is given to the source. 
Innocent Bystanders? Monetary Policy and Inequality in the U.S.

Olivier Coibion, Yuriy Gorodnichenko, Lorenz Kueng, and John Silvia

NBER Working Paper No. 18170

June 2012

JEL No. E2,E3,E4,E5

\section{$\underline{\text { ABSTRACT }}$}

We study the effects and historical contribution of monetary policy shocks to consumption and income inequality in the United States since 1980. Contractionary monetary policy actions systematically increase inequality in labor earnings, total income, consumption and total expenditures. Furthermore, monetary shocks can account for a significant component of the historical cyclical variation in income and consumption inequality. Using detailed micro-level data on income and consumption, we document the different channels via which monetary policy shocks affect inequality, as well as how these channels depend on the nature of the change in monetary policy.

Olivier Coibion

Department of Economics

College of William and Mary

115 Morton Hall

Williamsburg, VA 23188

and NBER

ocoibion@gmail.com

Yuriy Gorodnichenko

Department of Economics

508-1 Evans Hall \#3880

University of California, Berkeley

Berkeley, CA 94720-3880

and NBER

ygorodni@econ.berkeley.edu
Lorenz Kueng

Kellogg School of Management

Northwestern University

2001 Sheridan Road

Evanston, IL 60208

lorenz.kueng@gmail.com

John Silvia

Wells Fargo

Charlotte, NC

john.silvia@wellsfargo.com 
"In recent decades, the Fed has given way completely, at the highest level and with disastrous consequences, when the bankers bring their influence to bear... As the American economy begins to improve, influential people in the financial sector will continue to talk about the need for a prolonged period of low interest rates. The Fed will listen. This time will not be different."

Daron Acemoglu and Simon Johnson in "Who Captured the Fed?” 3/29/2012

\section{Introduction}

Recent popular demonstrations such as the Occupy Wall Street movement have made it clear that the high levels of inequality in the United States remain a pressing concern for a large swath of the population. While such movements have primarily focused their ire on private financial institutions and their perceived contribution to inequality and the Great Recession, the Federal Reserve (Fed) has not remained immune to their criticism. The prevalence of "End the Fed" posters at these events surely reflects, at least in part, the influence of Ron Paul and Austrian economists who argue that the Fed has played a key role in driving up the relative income shares of the rich through expansionary monetary policies. However, the view that monetary policy may have played a role in accounting for changes in inequality is shared by more than just Ron Paul followers. As the quote above from Acemoglu and Johnson illustrates, the notion that expansionary monetary policy primarily benefits financiers and their high-income clients, and may therefore be subject to institutional capture, has become more prevalent.

This view is at odds, however, with the common wisdom among economists as to the source of rising inequality. Skill-biased technological change (e.g. Bound and Johnson 1992), increased global trade (e.g. Feenstra and Hanson 2008) and changes in labor market institutions such as unionization (e.g. Card 2001) have long been the mechanisms which have received the most attention in the literature, while monetary policy is rarely mentioned as a likely candidate. The Austrian view is even more at odds with some who argue that it is contractionary — rather than expansionary — monetary policy which is partly to blame for the rise in inequality since the early 1980s. James K. Galbraith (1998), for example, has argued

"Rising wage inequality is neither inevitable nor mysterious nor necessary nor the dark side of a good thing, but was brought on, mainly, by bad economic performance... What caused bad economic performance? Economic policy, and very specifically monetary policy, changed. ... $[\mathrm{T}]$ he government abandoned the goal of full employment and instead turned its attention to a fight against inflation. For this purpose, only one instrument was deemed suitable: high interest rates brought into being by the Federal Reserve. There followed a repeated sequence of recessions... The high unemployment that these recessions produced generated the rise in inequality. For this, the Federal Reserve, under its reputable chairmen Arthur Burns, Paul Volcker and Alan Greenspan, stands primarily (though not solely) responsible.”

These contrasting views, not just about the quantitative importance of monetary policy in affecting economic inequality but even about the sign of the inequality response, reflect an emphasis on different channels through which monetary policy can potentially affect both income and consumption inequality. 
For example, Ron Paul and Austrian economists cite two specific channels. ${ }^{1}$ The first is the income composition channel, i.e. the fact that there is heterogeneity across households in terms of their primary sources of income. While most households rely primarily on labor earnings, others receive larger shares of the income from business and financial income. If expansionary monetary policy shocks raise profits more than wages, then those with claims to ownership of firms will tend to benefit disproportionately. Since the latter also tend to be wealthier (a fact we verify in our data), this channel should lead to higher inequality in response to monetary policy shocks. The second is the financial segmentation channel: if some agents frequently trade in financial markets and are affected by changes in the money supply prior to other agents, then an increase in the money supply will redistribute wealth toward those agents most connected to financial markets, as in Williamson (2009) and Ledoit (2009). To the extent that agents who participate actively in financial trades have higher income and consumption on average than unconnected agents, then this channel also implies that consumption inequality should rise after expansionary monetary policy shocks. An additional channel pushing in the same direction is the portfolio channel. If low-income households tend to hold relatively more currency than high-income households as in Erosa and Ventura (2002) or Albanesi (2007), then inflationary actions on the part of the central bank would represent a transfer from low-income households toward high-income households which would tend to increase consumption inequality.

Two other channels, however, will tend to move inequality in the opposite direction in response to expansionary monetary policy actions. The first is the savings redistribution channel: an unexpected increase in interest rates or decrease in inflation will benefit savers and hurt borrowers as in Doepke and Schneider (2006), thereby generating an increase in consumption inequality (to the extent that savers are generally wealthier than borrowers). The second is the earnings heterogeneity channel. Labor earnings are the primary source of income for most households and these earnings may respond differently for high-income and low-income households to monetary policy shocks. This could occur, for example, if unemployment disproportionately falls upon low income groups, as suggested by Galbraith and documented in Carpenter and Rogers (2004). Similar effects could arise even for the employed in the presence of different rates of wage rigidities across the income distribution (e.g. from unionization in production but not management), varying degrees of complementarity/substitutability with physical capital depending on agents' skill sets (since interest rates affect the relative price of capital and labor), or different endogenous labor supply responses reflecting specific household characteristics such as age and number of children which may systematically differ across the distribution. Heathcote, Perri and Violante (2010), for example, document that the labor earnings at the bottom of the distribution are most affected by business cycle fluctuations. In addition, the income composition channel could potentially push

\footnotetext{
${ }^{1}$ See for example http://www.ronpaul.com/on-the-issues/fiat-money-inflation-federal-reserve-2/.
} 
toward reduced-rather than increased, as suggested by Austrian economists-inequality after expansionary monetary policy. Because low-income households receive, on average, a larger share of their income from transfers (e.g. unemployment benefits, food stamps) than other households, and because transfers tend to be countercyclical, then this component of income heterogeneity could lead to reduced income inequality after expansionary monetary policy shocks.

In short, these different channels imply that the effect of monetary policy on economic inequality is a priori ambiguous. As a result, we turn to the data to assess whether U.S. monetary policy has contributed to historical changes in consumption and income inequality in the U.S., and if so, through which channels. To do so, we study the dynamic responses of measures of consumption and income inequality to monetary policy shocks identified as in Romer and Romer (2004). Our measures of inequality come from detailed household-level data from the Consumer Expenditures Survey (CEX) since 1980. These data are available on a higher frequency (quarterly) than other sources such as IRS data employed by Piketty and Saez (2003), with a high frequency being a necessary ingredient for analyzing the effects of monetary policy shocks. While the CEX does not include the very upper end of the income distribution (i.e. the top 1\%) which has played a considerable role in income inequality dynamics since 1980 (CBO 2011), the detailed micro-data do allow us to consider a wide range of inequality measures including for labor income, total income, consumption and total household expenditures. ${ }^{2}$

Using these measures of inequality, we document that monetary policy shocks have statistically significant effects on inequality: a contractionary monetary policy shock raises the observed inequality across households in income, labor earnings, expenditures and consumption. These results are robust to the time sample, such as dropping the Volcker disinflation period or all recession quarters, and are not qualitatively different when we employ alternative approaches to estimate impulse responses, such as VAR's, or also control for other macroeconomic shocks. They are also largely invariant to controlling for household size and other observable household characteristics such as age, education, or hours worked. In addition, monetary policy shocks appear to have played a non-trivial role in accounting for cyclical fluctuations in inequality over this time period. For example, forecast error variance decompositions suggest that the contribution of monetary policy shocks to inequality is of the same order of magnitude as the contribution of monetary policy shocks to other macroeconomic variables like GDP and inflation. Furthermore, monetary policy shocks can account for a surprising amount of the historical cyclical changes in income and consumption inequality, particularly since the mid-1990s.

Because of the detailed micro-level data in the CEX survey, we can assess some of the channels underlying the response of inequality to monetary policy shocks. For example, using data on the response

\footnotetext{
${ }^{2}$ As discussed in section 2, expenditures in our data include consumption purchases plus a number of other expenditures such as mortgage payments, auto purchases, and education expenses among others.
} 
of different percentiles of the labor earnings distribution, we show that contractionary monetary policy shocks are followed by higher earnings at the upper end of the distribution but lower earnings for those at the bottom, consistent with the channel emphasized by Galbraith. However, whereas Galbraith emphasized how unemployment after contractionary shocks would disproportionately affect those already at the low end of the income distribution, we find lower labor earnings at the low end of the distribution even for those households reporting themselves as full-time workers. Thus, there appears to be strong heterogeneity in the wage responses faced by different households. Furthermore, the rise in earnings inequality after contractionary monetary policy shocks is not driven solely by low-wage households facing lower wages. We also find that high-earnings households (such as the $90^{\text {th }}$ percentile) earn more labor income after contractionary shocks. Strikingly, the long-run responses of labor earnings and consumption for each percentile line up almost one-for-one, pointing to a close link between earnings and consumption inequality in response to economic shocks.

We also provide evidence that the income composition channel may play an important role in understanding the effects of monetary policy actions across households. For example, whereas aggregate labor earnings respond little on average to monetary shocks, we find that aggregate financial income rises sharply while business income declines after contractionary monetary policy shocks. While the much larger decline in business income than in labor earnings is in line with the income composition channel emphasized by Ron Paul and Austrian economists, it is offset for high income households by the increase in financial income. Further, a recent CBO report documents that the top $1 \%$ of the income distribution received approximately 30\% of their income from financial income, a much larger share than any other segment of the population. This suggests that total income for the top $1 \%$ likely rises even more than for most households in the CEX after contractionary shocks, so that our baseline results on income inequality are most likely a lower bound, since they exclude the top $1 \%$. We also find that income transfers play a key role in dampening the effects of monetary policy shocks on inequality. While labor earnings at the $10^{\text {th }}$ percentile -and to a lesser extent the $25^{\text {th }}$ percentile- decline after contractionary shocks, total income for these same percentiles is hardly affected. This reflects the fact that lower quintiles receive a much larger share of their income from transfers and that transfers tend to rise (albeit with a delay) after contractionary monetary shocks, thereby offsetting lost labor income. Hence, transfers appear to be quite effective at insulating the incomes of many households in the bottom of the income distribution from the effects of policy shocks. As a result, the dynamics of total income inequality primarily reflect fluctuations in the incomes of households at the upper end of the distribution and these dynamics are, in turn, dominated primarily by their labor earnings.

Because the CEX does not include reliable measures of household wealth, it is more difficult to assess some of the redistributive channels. For example, in the absence of consistent measures of the size 
of household currency holdings or financial market access, we cannot directly quantify the portfolio channel emphasized by Albanesi (2007) or the financial market segmentation channel in Williamson (2009). Nonetheless, to the extent that both channels imply that contractionary monetary policy shocks should lower consumption inequality, the fact that our baseline results go in precisely the opposite direction suggests that these channels, if present, must be small relative to others. However, in the case of the savings redistribution channel, we can provide some suggestive evidence of wealth transfers by identifying high and low net-worth households following the characterization of Doepke and Schneider (2006), namely that high net-worth households are older, own their homes, and receive financial income while low net-worth households are younger, have fixed-rate mortgages and receive no financial income. We find that while the average responses of total income and labor earnings are similar across the two groups, consumption and, to a lesser extent, total expenditures rise significantly more for high net-worth households than low net-worth households after contractionary monetary policy shocks.

Finally, we consider the sensitivity of these results to the nature of the monetary policy innovation. The Romer and Romer (2004) procedure identifies monetary policy shocks as innovations to the Federal Funds rate which are uncorrelated with the Fed's information set as represented by the Greenbook forecasts generated prior to each FOMC meeting. But as emphasized by Romer and Romer (2004), these innovations can reflect a number of factors such as changes in the preferences or objectives of the central bank and political constraints. While some of these changes can be interpreted as transitory factors, others might best be thought of as much more persistent. As a result, our results could be downplaying the potential contribution of monetary policy actions by lumping these different types of changes together. To investigate this, we consider a more specific kind of monetary policy shock, namely changes in the Federal Reserve's inflation target, identified either as in Coibion and Gorodnichenko (2011) or as in Ireland (2006). We show that permanent decreases in the inflation target also systematically increase income and consumption inequality for both measures of the inflation target and that forecast error variance decompositions point to contributions from these shocks in line with those found using baseline Romer and Romer shocks. However, shocks to the inflation target imply larger historical contributions of monetary policy to consumption and expenditure inequality and, to a lesser extent, income inequality. This is particularly the case for the early 1980s, where the inflation target shocks associated with the Volcker disinflation account for the large and very persistent increases in consumption and expenditure inequality.

Monetary policy therefore may well have played a more significant role in driving recent historical inequality patterns in the U.S. than one might have expected. These results are interesting for several reasons. First, the potential contribution of monetary policy to inequality has received relatively little attention in the economics literature, despite the fact that many outside of mainstream economics 
emphasize a causal link between the two. ${ }^{3}$ Understanding and quantifying the sources of inequality is a first step to determining what kinds of policies, if any, are most appropriate to address it. The heterogeneity in consumption and income responses across households is also of immediate relevance to monetary economists and policymakers for understanding the monetary transmission mechanism. In addition, some research has linked rising inequality to credit booms and financial crises (Rajan 2010, Kumhof and Ranciere 2011), therefore suggesting a potential link from inequality to macroeconomic stability. There is also a growing macroeconomics literature emphasizing agent heterogeneity which is explicitly interested in the dynamics of consumption and income inequality, as well as the implications of heterogeneity across agents for optimal policy design. However, a recent survey of this literature (Heathcote, Storesletten, and Violante 2009) suggests that the issues surrounding monetary policy have not received much attention within this class of models. One interpretation of our results could be as providing a set of stylized facts about the conditional responses of income, earnings and consumption patterns across households to monetary policy shocks that can be used to calibrate and differentiate between different classes of heterogeneous agent models, in the same spirit as the use of monetary policy shocks by Christiano, Eichenbaum and Evans (2005) to estimate the parameters of New Keynesian models with a representative agent. Finally, recent work (e.g. Heathcote, Perri and Violante 2010) has emphasized both the strong cyclical component to economic inequality but also the variation in the behavior of inequality across business cycle episodes. With changes in monetary policy-making having been proposed as a potential contributor to the Great Moderation and its unique business cycle properties (e.g. Clarida, Gali and Gertler 2000), one can naturally consider monetary policy also as affecting cyclical inequality patterns.

The paper is structured as follows. Section 2 discusses the Consumer Expenditure Survey, the construction of inequality measures and their unconditional properties. Section 3 presents the main results on the effects of monetary policy shocks on income, labor earnings, expenditure and consumption inequality. Section 4 assesses the wealth effects of monetary policy shocks while section 5 considers the implications of changes in the inflation target. Section 6 concludes.

\section{Measuring Inequality}

In this section, we briefly describe the Consumer Expenditure Survey and the construction of measures of inequality for total income, wage income, consumption and total expenditures.

\footnotetext{
${ }^{3}$ One exception is Romer and Romer (1998) who focus on the effects of monetary policy on poverty. Another, Galbraith, Giovannoni and Russo (2007), relies on the term of structure of interest rates as a measure of exogenous policy actions to quantify the effects of monetary policy on earnings inequality.
} 


\subsection{The Consumer Expenditure Survey}

The Consumer Expenditure Survey (CEX), which is provided by the Bureau of Labor Statistics (BLS), consists of two separate surveys, the Interview Survey and the Diary Survey. In this study we only use data from the Interview Survey since the Diary Survey covers only expenditures on small items that are frequently purchased, mostly related to food. The Interview Survey provides information on up to 95\% of the typical household's consumption expenditures.

The CEX is the most comprehensive data source on household consumption in the U.S. and is used for the construction of CPI weights. ${ }^{4}$ The raw data of the Interview Survey can be accessed from the Inter-university Consortium for Political and Social Research (ICPSR) at the University of Michigan. The CEX is a monthly rotating panel, where households are selected to be representative of the US population, and is available on a continuous basis since 1980. About 1,500-2,500 households are surveyed in any given month. Each household is interviewed once per quarter, for at most five consecutive quarters, although the first interview is used for pre-sampling purposes and is not available for analysis. In each interview the reference period for expenditures covers the three months prior to the interview month. However, the within-interview variation is much lower than the between-interview variation, suggesting that many households provide average monthly expenditures instead. To reduce measurement error, we therefore aggregate the household's monthly expenditures to quarterly expenditures. Hence, "household time” is quarterly, but since the CEX is a monthly rotating panel, the overall sampling frequency of the expenditure data is monthly.

Non-durable consumption includes among others food, alcohol and tobacco, and gasoline and other fuel. Service consumption includes household utilities, household operations, service charges, recreational services, public transportation, and personal care services. We define household consumption as the sum of non-durables, services, and expenditures on durable goods, e.g. furniture and furnishing, jewelery and watches, recreational goods, and personal care durables. We also construct a broader measure of household expenditures by adding mortgage and rent payments, health expenditures, education spending and other expenses to household consumption levels.

\footnotetext{
4 The unit of measurement in the CEX is a so-called Consumer Unit (CU), which the BLS defines as "(1) all members of a particular household who are related by blood, marriage, adoption, or other legal arrangements; (2) a person living alone or sharing a household with others or living as a roomer in a private home or lodging house or in permanent living quarters in a hotel or motel, but who is financially independent; or (3) two or more persons living together who use their incomes to make joint expenditure decisions. Financial independence is determined by spending behavior with regard to the three major expense categories: Housing, food, and other living expenses. To be considered financially independent, the respondent must provide at least two of the three major expenditure categories, either entirely or in part." (http://www.bls.gov/cex/csxfaqs.htm\#q3) Therefore, a household can consist of more than one CU. Expenditures are measured at the level of the CU, while certain additional characteristics are available for each member of the CU.
} 
We correct sample breaks due to slight changes in the questionnaire of the following variables: food at home (1982Q1-1988Q1), personal care services (2001Q2), and occupation expenditures (2001Q2). To further improve the quality of the data, we drop the following observations: interviews with more or less than three monthly observations; households reporting zero food or total expenditures; and observations with negative expenditures where there should not be any. As recommended by the BLS, we sum expenditures that occur in the same month but are reported in different interviews. Overall, this procedure eliminates about $7 \%$ of the observations in the initial sample. Income data is asked in the first and last interview (i.e. interviews 2 and 5 in CEX terminology), and financial data is only asked in the last interview. The reference period for income flows covers the twelve months before the interview. All nominal variables are deflated using the CPI-U. To make the results comparable across sub-samples and with studies that use aggregate data, we use survey sample weights.

Much work has been devoted to assessing the quality of the CEX relative to other data. Heathcote, Perri and Violante (2010), for example, compare income inequality data in the CEX with equivalent measures from the Panel Study of Income Dynamics (PSID) and the Current Population Survey (CPS). They find strong comovement among pre-tax earnings inequality measures from all three surveys. Attanasio (2003) and Attanasio, Battistin and Ichimura (2004) similarly document the consistency of wage inequality in the CEX and the CPS. More concern has been raised with respect to underreporting of consumption in the CEX. Krueger et al. (2010), Aguiar and Bils (2011) and Attanasio, Hurst, and Pistaferri (2012) for example document that the CEX underreports consumption relative to aggregate data and that this underreporting has become more severe over time. On the other hand, Bee, Meyer, and Sullivan (2012) compare reported consumption spending data in the CEX to comparable data from the national income accounts data and find that the CEX conform closely to aggregate data for large consumption categories. For our purposes, the potential underreporting of consumption in the CEX is less of a concern, since we will focus on cyclical fluctuations in consumption inequality. In addition, our empirical specifications will focus on changes in inequality rather than overall levels. Nonetheless, the potential limitations in the quality of the CEX survey data are an important caveat to bear in mind.

\subsection{Measures of Inequality}

Given the availability of household data on both consumption and income, the CEX allows us to study the behavior of both forms of inequality. To do so, we focus on three ways of measuring each form of inequality: Gini coefficients of levels, cross-sectional standard deviations of log levels, and differences between individual percentiles of the cross-sectional distribution of log levels. The Gini coefficient has long been used to measure inequality. It summarizes via a single number between 0 and 1 the extent to which a variable is equally allocated across different components of the distribution. In addition to Gini 
coefficients, we will also use the cross-sectional standard deviation of log values. Taking logs allows us to diminish the sensitivity to outliers, but requires us to drop observations equal to zero, in contrast to the Gini coefficient. Finally, we will use the difference between the $90^{\text {th }}$ percentile and the $10^{\text {th }}$ percentile of the log levels in each distribution. Like the cross-sectional standard deviation, the use of logs requires the elimination of observations with values of zero. But the advantages of the percentile differential are that it will conform more closely to the behavior of individual percentiles, which we will look at in subsequent sections, and that it is less sensitive to extreme observations in the tails of the distributions.

Given the detailed data in the CEX, we will consider two forms of inequality for income and consumption each. On the income side, we first construct measures of labor earnings inequality across households. Given the survey nature of the data, the advantage of labor earnings is that they are likely to be known with the highest precision by households relative to other forms of income. The disadvantage is, of course, that labor income is only one component of most households' income. As a result, we also construct measures of total income inequality based on labor earnings as well as financial income, business income and transfers for each household. Because individuals in the CEX are asked about their income only in the first and last quarters of their participation in the survey and the BLS imputes income for periods in between, we use only those individuals who are reporting their income in each survey to construct measures of income and earnings inequality. Hence, the sample used to construct income inequality measures each quarter is only a subset of the total population in the survey that period. We will focus primarily on pre-tax measures of total income, although we also present after-tax income inequality measures and show that our results are robust to this alternative measure. ${ }^{5}$ All labor income is pre-tax however. In addition, our baseline measures of labor earnings reflect both wages and hours worked. We subsequently present robustness checks in which we restrict the sample to full-time working individuals, but measuring hours is always problematic and the CEX is no exception.

Table 1 reports correlations among the different measures of inequality for both income and labor earnings. The different measures of income inequality measures are highly correlated with one another, with correlations of 0.89 or above over the entire sample from 1980Q1 to 2008Q4, when the zero bound on interest rates becomes binding. The correlations between the different measures of earnings inequality are generally lower, particularly for the Gini coefficient. This reflects the fact that both the crosssectional standard deviation and the $90^{\text {th }}-10^{\text {th }}$ percentile measures include only households which report positive wage income, whereas the Gini coefficient also takes into account those households reporting no wage income. The high correlation between the standard deviation and the $90^{\text {th }}-10^{\text {th }}$ percentiles $(0.85)$ is in line with those found for total income measures, which is consistent with the notion that the lower

\footnotetext{
${ }^{5}$ Following Kueng (2012) we compute tax burdens using the TAXSIM calculator of the NBER; see Feenberg and Coutts (1993). The code is available at http://www.nber.org/ taxsim/to-taxsim/cex-kueng.
} 
correlation of each with respect to the Gini coefficient reflects the differential treatment of individuals reporting no income.

Similarly, we construct both a narrow and broad measure of consumption inequality. The narrow measure, which we refer to as consumption inequality, includes the same categories as in Parker (1999). Consumption goods in this category include non-durables, services, and some durable goods (household appliances, entertainment goods like televisions, furniture) but do not include large durable purchases such as house and car purchases. However, we also define a broad measure of consumption, which we refer to as total expenditures, which includes the previous definition of consumption as well as mortgage payments, purchases of cars, medical supplies and services, and tuition and books for schooling among other items. In contrast to income measures, consumption and expenditure data for individuals in the survey is measured every period, so consumption and inequality measures use the entire population in the survey each period subject to the caveats discussed in section 2.1. For both consumption and expenditures, we first aggregate all reported purchases within each definition at the level of the household, then construct inequality measures across households.

All of our baseline measures of inequality are raw, i.e. do not control for any household characteristics like the number of household members, age, education, etc. This is because some of the channels by which monetary policy might affect inequality could be systematically related to some of these observables. For example, the redistribution of wealth from borrowers to savers should likely be related to the age of households. Controlling for age would make it more difficult to identify this kind of channel. Similar logic applies to other household characteristics. However, while our baseline measures do not control for any household observables, we will consider a number of robustness checks in which we do control for household characteristics.

Table 1 documents a high correlation across different measures of expenditure inequality, ranging from 0.75 to 0.89 . In contrast, correlations among the consumption measures are smaller, ranging from 0.80 down to 0.45 . Table 1 also reports correlations across income and expenditure inequality measures as well as their volatilities. With respect to the latter, income and earnings inequality measures have approximately the same volatility, while the volatility in expenditure inequality tends to be higher than that of consumption inequality. Correlations between different forms of inequality vary widely. For example, the correlation between income and earnings inequality using Gini coefficients is very high at 0.82 , while correlations between the two using either the standard deviation or the $90^{\text {th }}-10^{\text {th }}$ percentiles are much lower, at 0.22 and 0.12 respectively. Similar results obtain for the correlations of income with consumption inequality and the correlations between earnings and consumption inequality. The correlation between expenditures and consumption inequality is consistently very positive, as is that between earnings and expenditure inequality. 


\subsection{Unconditional Properties of Inequality Measures}

Figure 1 plots the historical inequality measures of income, labor earnings, expenditures and consumption inequality measures from the CEX based on the cross-sectional standard deviation (Panel A), Gini coefficient (Panel B) and the $90^{\text {th }}$ to $10^{\text {th }}$ percentile differential (Panel C), averaged over the previous and subsequent quarter to illustrate more clearly business cycle and low-frequency variations. Consistent with results documented in the literature (Krueger and Perri 2005, Meyer and Sullivan 2010), our measures of total income inequality are all trending up over time. A similar pattern occurs for labor earnings inequality when measured using the Gini coefficient but not when measured using the cross-sectional standard deviation nor the $90^{\text {th }}-10^{\text {th }}$ percentile differential, a feature of the data also documented in Heathcote, Perri and Violante (2010). There is a sharp increase in all forms of inequality in the early 1980s. Income inequality rises over the course of the 1990s, while little such movement is apparent for consumption or expenditure inequality measures. Finally, there is a noticeable decline in expenditure inequality over the course of the 2000s despite there being no such decrease in income inequality.

The figures therefore reveal some evidence of cyclical behavior in inequality measures, consistent with Heathcote et al. (2010). Table 2 presents unconditional correlations between inequality measures and quarterly inflation, the unemployment rate and the Federal Funds rate. All series are HP-filtered prior to measuring correlations so that the latter primarily reflect business cycle fluctuations rather than trends. Correlations of different forms of inequality with the inflation rate are very small and somewhat negative. Similar results obtain with interest rate correlations. Labor earnings inequality is weakly positively correlated with the unemployment rate and negatively with inflation. Expenditure and consumption inequality are more strongly negatively correlated with the unemployment rate. This could be interpreted as being consistent with a wealth channel, whereby even if income inequality varies little with the business cycle, cyclical fluctuations in asset prices have significant effects on wealth holdings of individuals, leading to lower consumption and expenditures of the wealthy during recessions. Overall however, the unconditional correlations do not point toward very strong links between business cycles and inequality patterns.

\section{Effects of Monetary Policy Shocks on Inequality}

In this section, we present baseline results for the effects of monetary policy shocks on measures of income inequality. We first discuss the construction of monetary policy shocks, then present results quantifying the effects of these shocks on different forms of inequality in the U.S., as well as number of robustness checks. We also present results on how monetary policy shocks affect different components of 
the distributions, whether mobility within the distribution changes after monetary shocks, and the economic importance of monetary policy for inequality dynamics.

\subsection{The Identification of Monetary Policy Shocks}

To characterize the effects of monetary policy on inequality in the U.S., we follow Romer and Romer (2004, RR henceforth) to identify innovations to monetary policy purged of anticipatory effects related to economic conditions. RR first construct a historical measure of changes in the target Federal Funds rate (FFR) at each FOMC meeting from 1969 until 1996. Using the real-time forecasts of the Fed staff presented in the Greenbooks prior to each FOMC meeting (denoted by F), RR construct a measure of monetary policy shocks defined as the component of policy changes from each meeting which is orthogonal to the Fed's information set, as embodied by the Greenbook forecasts. Specifically, they estimate

$$
\begin{gathered}
\Delta f f_{m}=\alpha+\beta f f b_{m}+\sum_{i=-1}^{2} \gamma_{i} F_{m} \Delta y_{m, i}+\sum_{i=-1}^{2} \lambda_{i}\left(F_{m} \Delta y_{m, i}-F_{m-1} \Delta y_{m, i}\right)+\sum_{i=-1}^{2} \varphi_{i} F_{m} \pi_{m, i} \\
+\sum_{i=-1}^{2} \theta_{i}\left(F_{m} \pi_{m, i}-F_{m-1} \pi_{m, i}\right)+\mu_{i} F_{m} u e_{0}+\varepsilon_{m}
\end{gathered}
$$

where $m$ denotes the FOMC meeting, $f f b_{m}$ is the target FFR going into the FOMC meeting, $F_{m} \Delta y_{m, i}$ is the Greenbook forecast from meeting $m$ of real output growth in quarters around meeting $m$ ( -1 is previous quarter, 0 is current quarter, etc.), $F_{m} \pi_{m, i}$ are Greenbook forecasts of GDP deflator inflation, and $F_{m} u e_{0}$ are Greenbook forecasts of the current quarter's average unemployment rate. The estimated residuals $\hat{\varepsilon}_{m}$ are then defined by RR as monetary policy shocks.

We extend the RR dataset on monetary policy shocks until December 2008 as follows. First, we incorporate more recent changes in the target FFR decided upon at regular FOMC meetings. Second, we extend the Greenbook forecasts until December 2006, the most recent period through which the Federal Reserve has released them. Third, we use consensus forecasts from the Blue Chip Economic Indicators in place of Greenbook forecasts for the FOMC meetings in 2007 and 2008. The dataset therefore extends until the zero-bound on interest rates became binding in December 2008. Estimating the exact same specification as RR upon this extended dataset since January 1969 yields a sequence of monetary policy shocks at the frequency of FOMC meetings. We then construct a quarterly measure of monetary policy shocks by averaging the orthogonalized innovations to the FFR from each meeting within a quarter. The resulting shock series are plotted in Figure 2, starting in 1980Q1. Consistent with the results documented in RR, the shocks are particularly large and volatile in the early 1980s during the Volcker disinflation. The shocks also identify periods in which policy was distinctly more contractionary than usual 
conditional on real-time forecasts. For example, the "pre-emptive strike" against inflation in 1994-1995 is visible as a period of consistently positive MP shocks, as is the period of 2005-2006. The 2000-2004 period, on the other hand, suggests more expansionary policy than would have been typical given staff forecasts of macroeconomic conditions, consistent with Taylor (2007).

Before turning to the effects of monetary policy shocks on inequality, we first investigate how contractionary monetary policy actions affect macroeconomic aggregates, financial variables, as well as more detailed income and consumption aggregates. To do so, we follow RR and estimate

$$
x_{t}=c+\sum_{j=1}^{J} \alpha_{j} x_{t-j}+\sum_{i=0}^{I} \beta_{i} \hat{\varepsilon}_{t-i}+v_{t}
$$

where $x$ is the variable of interest and the $\hat{\varepsilon}$ are monetary policy innovations. With the exception of real stock prices and interest rates, we use first-differences of macroeconomic variables in estimating (2) and generate accumulated impulse responses to monetary policy shocks from the estimated $\alpha_{j}$ and $\beta_{i}$. Standard errors are as in Newey-West (1987). Confidence intervals for impulse responses are constructed using a bootstrap in which we draw repetitively from the estimated distribution of coefficients of equation (2) and construct impulse responses associated with each draw of coefficients. These yield a distribution of impulse responses which will characterize the uncertainty associated with impulse responses. Over the entire sample, we set $J=8$ and $I=12$ as in RR but use $J=4$ and $I=8$ over the more restricted sample. All estimates are at the quarterly frequency.

The results are presented in Figure 3 using data from 1969:Q1 to 2008Q4, the entire period over which monetary policy shocks are available, as well as the more restricted sample since 1980Q1. Over the entire sample, contractionary monetary policy shocks lower real GDP, consumption and investment while raising unemployment. Both short-term and long-term interest rates rise immediately while inflation declines after a two-year lag. These results are consistent with a long empirical literature on the macroeconomic effects of monetary policy shocks (e.g. Christiano, Eichenbaum and Evans 1999). The impulse responses point to smaller real effects of monetary policy shocks since 1980, in line with Boivin and Giannoni (2006), although the differences over the two samples are not statistically significant.

In addition, we consider the effects of monetary policy shocks on real stock prices (Dow Jones Industrial Average deflated by the GDP deflator) and real housing prices (Case-Shiller price index deflated by the GDP deflator), both of which are important components of household wealth. Real stock prices decline on impact (as in Bernanke and Kuttner 2005) but eventually rise. In contrast, real housing prices, the major financial asset for most households, decline gradually after one to two years. This suggests one channel through which monetary policy might affect households differently: to the extent that households' wealth is not allocated in the same manner across assets, then those households with 
relatively more wealth in stock holdings would, ceteris paribus, experience persistent increases in wealth relative to households whose wealth lies primarily in their home.

Figure 3 also presents responses of different sources of income to contractionary monetary policy shocks. The response of real wages is not statistically different from zero over either sample, while business income drops rapidly and significantly. The latter is consistent with the income composition channel emphasized by Austrians. Financial income, on the other hand, rises significantly and persistently both over the entire period and in the shorter sample since 1980Q1. Total income from transfers drops over the first year after a shock before rising approximately two years after the shock, temporarily over the entire sample but persistently so when looking at the period since 1980. Thus, these results also suggest that heterogeneity in income sources across households may also lead to distributional consequences to monetary policy actions. Contractionary monetary policy will tend raise incomes for those who receive a lot of financial income but lower incomes for business owners.

\subsection{The Effects of Monetary Policy Shocks on Inequality}

To quantify the overall effects of monetary policy shocks on economic inequality, we again estimate equation (2) using inequality measures for total income, labor earnings, total expenditure and consumption, defined as in section 2 . We do so for each form of inequality using three different measures of inequality for each: the cross-sectional standard deviation (of logged values), the Gini coefficient, and the difference between the $(\log ) 90^{\text {th }}$ percentile and the $(\log ) 10^{\text {th }}$ percentile. ${ }^{6}$ While monetary policy shocks are generated regressors, Pagan (1984) shows that if the null hypothesis is $\beta_{i}=0 \forall i \in[0, I]$, then standard errors need no adjustment. Given the consensus view among mainstream economists that monetary policy has played little role in affecting economic inequality in the U.S., this is a reasonable null to hold. Furthermore, because monetary policy shocks are the residuals from estimates of (1), they will be largely orthogonal to contemporaneous economic conditions and other factors absorbed into the error term $v$, further justifying the use of unadjusted standard errors. In estimating equation (2) for inequality measures, we consistently use a lag structure of $J=4$ and $I=8$ quarters.

Figure 5 presents the accumulated impulse responses from estimates of equation (2) for each form of inequality (income, labor earnings, expenditure and consumption) and measure of that inequality (standard deviation, Gini, and $90^{\text {th }}$ to $10^{\text {th }}$ percentile differential) using data from 1980Q1 until 2008Q4

\footnotetext{
${ }^{6}$ In the case of $90^{\text {th }}-10^{\text {th }}$ percentile differentials, we estimate equation (2) for changes in the $90^{\text {th }}$ and $10^{\text {th }}$ percentiles separately using seemingly-unrelated regressions (SUR), then construct the impulse response and standard errors of the difference between the two from the SUR estimates. This is done because, if each percentile has independent measurement error due to sampling, taking the difference between the two will increase the measurement error in the series and bias the estimation procedure.
} 
and the associated one standard deviation confidence intervals. ${ }^{7}$ The results for both income and labor earnings inequality point to statistically significant effects of monetary policy shocks on inequality. In each case, the estimates point to higher long-run levels of income and salary inequality after contractionary monetary policy shocks, although the degree of statistical significance varies with the measure used. The estimates for income inequality are almost identical using after-tax and pre-tax income inequality, so we will focus exclusively on pre-tax measures henceforth. The results for consumption and expenditure inequality are even more supportive of an effect of monetary policy shocks on inequality, particularly for expenditure inequality. With expenditures, each measure of inequality points to a statistically significant and highly persistent increase in inequality after a contractionary monetary policy shock. Furthermore, the point estimates for expenditures are consistently larger than for other forms of inequality, pointing to monetary policy shocks having disproportionately large effects on expenditure inequality relative to other forms of economic inequality. In short, across all forms of inequality and the different ways of measuring each type of inequality, the impulse responses indicate that contractionary monetary policy shocks are associated with higher levels of economic inequality.

To verify the robustness of this result, we consider a wide set of robustness checks. First, because estimated impulse responses can be severely biased if the lag selection is too short, we consider the sensitivity of our results to longer lag lengths, namely $J=8$ and $I=12$ as in RR. The results using the Gini coefficient are presented in the top row of Appendix Figure 1. The estimated effects on total income inequality and labor earnings inequality are qualitatively unchanged, while those for expenditure and consumption inequality are strengthened: for the latter, the effects are much larger and are now statistically significant at longer horizons. A second check is to assess whether these results are driven by the Volcker disinflation: this period includes particularly contractionary monetary shocks and increases in most measures of inequality. At the same time, Coibion (2010) documents that the estimated effects of monetary policy shocks on macroeconomic variables can be quite sensitive to the treatment of this time period. The middle row of Appendix Figure 1 therefore presents results starting in 1985Q1. Again, the results are qualitatively unchanged indicating that the Volcker disinflation is not driving the empirical results. In the bottom row of Appendix Figure 1, we drop all quarters during NBER-dated recessions and again the results are qualitatively unchanged: while the estimated effects on consumption inequality are less precise, those for total income and labor earnings inequality are, if anything, larger. Thus, these results suggest the increased economic inequality after contractionary monetary policy shocks observed in Figure 5 is not sensitive to the lag structure or specific business cycle episodes.

\footnotetext{
${ }^{7}$ Note that we include four lagged values of monetary policy shocks from 1979 to avoid shortening the time sample too much from the use of a long lag structure for monetary policy shocks.
} 
In addition, we want to consider the robustness of this stylized fact to the empirical procedure. One alternative approach to estimating the response of a variable to shocks is to directly estimate the moving average representation of that variable in terms of the shock

$$
x_{t}=c+\sum_{i=0}^{N} \beta_{i} \hat{\varepsilon}_{t-i}+v_{t}
$$

as in Cochrane and Piazzezi (2002). An advantage of this approach is that it directly recovers the impulse response coefficients, but it may yield less precise results than the RR procedure in short samples because, for the latter, the lagged values of the dependent variable will partially control for other shocks. The top row of Appendix Figure 2 presents estimated effects of monetary policy shocks on inequality from applying equation (3) with $N=20$. For total income and labor earnings inequality, the point estimates of the impulse response are similar, but the larger standard errors make the results only marginally statistically different from zero. In contrast, the estimated effects for consumption and expenditure inequality are even more pronounced than using our baseline approach.

Another robustness check we consider is to control for other macroeconomic shocks in the estimation of equation (2). This can potentially increase the precision of the estimates in short samples. We consider three specific shocks as controls: technology shocks $\left(\zeta^{T}\right)$ as in Gali (1999), oil supply shocks $\left(\zeta^{O}\right)$ from Kilian (2009) and tax shocks $\left(\zeta^{F}\right)$ from Romer and Romer (2010). We then estimate an augmented version of (2)

$$
x_{t}=c+\sum_{j=1}^{4} \alpha_{j} x_{t-j}+\sum_{i=0}^{8} \beta_{i} \hat{\varepsilon}_{t-i}+\sum_{s \in\{T, O, F\}} \sum_{i=0}^{2} \gamma_{i} \hat{\zeta}_{t-i}^{s}+v_{t}
$$

including contemporaneous values and two lags of each shock. Results for the Gini coefficient are plotted in the middle row of Appendix Figure 2. In each case, the estimated effects of contractionary monetary policy shocks on inequality are larger than in our baseline. Thus, controlling for other macroeconomic shocks in the estimation of impulse responses only strengthens our results.

An alternative approach to controlling for dynamics of non-monetary factors is to estimate impulse responses from a VAR. We apply this approach using real GDP, the unemployment rate, the price level, a measure of monetary policy and a measure of economic inequality as endogenous variables in a VAR and identify monetary policy innovations using a Choleski decomposition applied to this ordering. The measure of monetary policy included in the VAR is the cumulative sum of monetary policy innovations from (1), as in Romer and Romer (2004) rather than the Federal Funds rate. This is because the former has been purged of information about future macroeconomic conditions embodied by the Greenbook forecasts. We use 4 lags in the VAR and the same time sample of 1980Q1 to 2008Q4. The estimated responses to monetary policy shocks from the VAR are presented in the bottom row of 
Appendix Figure 2. The results again point to contractionary monetary policy shocks raising all measures of economic inequality, with the effects on total expenditure and consumption inequality being noticeably stronger than when using our baseline specification. In short, these results all indicate that the effects of monetary policy shocks on inequality are remarkably robust to the empirical procedure used.

Finally, we want to ensure that our results are robust to household characteristics. Our baseline measures of economic inequality across households do not control for a number of household characteristics such as number of people in the household, age of household members, education, etc... Because work on inequality sometimes normalizes household income and consumption by the number of individuals in the household, we also consider measures of income and consumption inequality across households measured using an OECD equivalence scale. ${ }^{8}$ The top row of Appendix Figure 3 shows the effects of monetary policy shocks on these alternative measures of inequality (using the cross-sectional standard deviation of logged household values) relative to our baseline estimates. The results are even stronger than in our baseline: the estimated effects of monetary policy shocks on inequality are almost always higher and are more statistically significant than in our baseline.

We also consider measures of inequality after controlling for factors which would contribute to differential income and consumption levels across households. For example, we control for age of the head of household (quartic polynomial), the number of adults and the number of children in the household, race, the education level of the head of household, and a number of other characteristics by first regressing logged household income, earnings, consumption and expenditures on these observables. We then define inequality as the cross-sectional standard deviation of the residuals across households (since Gini coefficients cannot be constructed using residuals). The middle row of Appendix Figure 3 plots the estimated responses of these narrower measures of inequality to contractionary monetary policy shocks relative to our baseline estimates for the raw cross-sectional standard deviation. Again, the estimates are qualitatively unchanged and, if anything, stronger with the sole exception being consumption inequality.

To control for possible labor supply responses, we consider the restricted set of households which report either both members working 35-45 hours a week all year or one member working 35-45 hours a week and the other less than 5 (for single-adult households, we focus on those in which reported hours are approximately 40 hours). Thus, this eliminates most households reporting part-time work for which adjusting the number of hours is much more likely. We then construct inequality measures controlling for

\footnotetext{
${ }^{8}$ The OECD equivalence scale assigns a value of 1.0 to the head of the household, a value of 0.7 to each additional adult (17+), and a value of 0.5 to each child. We do not control for household size in the baseline because one can interpret the number of household members as a choice variable reflecting a utility flow equivalent to foregone consumption. That is, a household may choose to have an additional child because the utility derived from the presence of the child exceeds the loss in consumption associated with an additional dependent. In this case, it is not clear that one would want to treat household consumption as lower because of the presence of an additional member.
} 
household size, and other household observables as before but now for households with either one or two full-time workers. The bottom row of Appendix Figure 3 plots the effects of monetary policy shocks on these alternative inequality measures. The responses of earnings, expenditure and consumption inequality are larger and more statistically significantly different from zero than our baseline results. The point estimates for total income inequality are slightly smaller than in our baseline, but continue to point toward higher income inequality after contractionary monetary policy shocks.

In short, the increased economic inequality, both in terms of income and consumption, after contractionary monetary policy shocks is remarkably robust. It obtains for different measurements of economic inequality (i.e. Gini vs. percentile differentials vs. standard deviations), is not driven exclusively by the Volcker disinflation or recessions, can be recovered from a number of empirical methods, and holds when controlling for different household characteristics and labor supply decisions.

\subsection{Why Does Inequality Increase After Contractionary Monetary Policy Shocks?}

The evidence in section 3.2 suggests that contractionary monetary policy actions raise consumption and income inequality. We now investigate some of the mechanisms underlying this inequality response. Specifically, we focus on the extent to which monetary policy shocks affect consumption and income in the upper and bottom ends of the distribution. To do so, we consider the responses of different percentiles of the consumption and income distributions to monetary policy shocks. Because of the nature of the survey data, the way these measures are constructed for income measures versus consumption measures are different. In the case of both income and labor earnings, we construct percentiles each quarter from the distribution of households reporting income and earnings that quarter. Since households are asked about their income and earnings over the last twelve months in only the first and fourth quarter in which they participate in the survey, these measures of different percentiles of the earnings and income distribution reflect a changing composition of households each quarter. In contrast, because consumption and expenditures are tracked each quarter, we can control for the potentially changing composition and ranking of households across periods when we measure the changes in consumption and expenditures by percentile each quarter. Specifically, in each quarter, we rank households according to either their consumption or expenditures. Then, we isolate those households near each percentile of interest $\left(90^{\text {th }}\right.$, $75^{\text {th }}, 50^{\text {th }}, 25^{\text {th }}$ and $10^{\text {th }}$ ) that quarter and construct the percent changes in their consumption and expenditures. Applying this procedure each quarter yields a time series of percent changes for each percentile which controls for composition effects. We then recover the responses of each percentile to contractionary monetary policy shocks from estimating equation (2) for percentile changes.

We show the estimated effects of monetary policy shocks on different percentiles of the income, labor earnings, expenditure and consumption distribution in Figure 5. With respect to earnings responses, 
the results suggest that, after about two years, wage earnings for those in the upper end of the salary income distribution rise while those at the lower end of the salary income distribution see their earnings fall. With the response of the $75^{\text {th }}$ percentile being between that of the $90^{\text {th }}$ and the $50^{\text {th }}$ percentiles and the response of the $25^{\text {th }}$ percentile being between that of the $10^{\text {th }}$ and the $50^{\text {th }}$, these results point to contractionary monetary policy shocks having heterogeneous effects on labor earnings which raise labor incomes at the upper end of the distribution while lowering that of those at the bottom end of the distribution. Strikingly, the results are highly symmetric: while the response of the median of the distribution is essentially zero, earnings at the $90^{\text {th }}$ percentile rise by almost the same percentage as the decline in earnings of the $10^{\text {th }}$ percentile.

In Appendix Figure 4, we document first that these responses of labor earnings are qualitatively robust to controlling for hours worked by restricting the sample to those households where either both adults report full-time work or one reports full-time work and the other reports no working hours. Restricting the sample to these households lowers the long-run effects of monetary policy shocks for each percentile by approximately $1 \%$ point such that real wages weakly fall for all percentiles but does not affect their relative magnitudes. This suggests that households with more flexible hours increase their hours worked proportionally along the income distribution, thereby raising earnings at each percentile. We also plot responses controlling for household observables as well as responses controlling for observables but restricted to households with full-time workers. In both cases, the relative ordering of earnings responses by percentile is unchanged but the quantitative differences are reduced. However, this reduced dispersion in the response of labor earnings contrasts with that obtained using the cross-sectional standard deviation of logged earnings, controlling for household observables as well as when controlling for both observables and hours worked. Thus, the extent to which the differential response of labor earnings across the income distribution reflects factors such as education, age, race, and other observables as well as labor supply is unclear.

The results with respect to total incomes are also suggestive of an effect of monetary policy shocks on income inequality but to a smaller extent than with wage income. The response of the $90^{\text {th }}$ percentile of the income distribution is highest starting two years after the shock while that of the $10^{\text {th }}$ percentile is lowest, but the difference between the two is only about half of that implied by earnings differentials. Furthermore, unlike the responses of earnings percentiles in which higher percentiles consistently saw higher earnings responses, the $25^{\text {th }}$ percentile of the income distribution rises relative to both the $50^{\text {th }}$ and $75^{\text {th }}$ percentiles of the income distribution, so monetary policy shocks have less monotonic effects on the total income distribution than on wage incomes.

The reason why monetary policy shocks have more muted effects on total incomes of the $10^{\text {th }}$ and $25^{\text {th }}$ percentiles than might be expected from the response of their labor earnings lies in the different 
sources of their total incomes relative to other households. Table 3 presents a decomposition of total income for each quintile (measured by consumption of nondurables and services as a proxy for permanent income) for the 1980s, 1990s and 2000s. The most striking result of this decomposition is the rising importance of labor earnings as a share of total income at higher quintiles of the distribution. For example, in the 2000s, labor income accounted for over $80 \%$ of total income for the highest quintile, $74 \%$ for the middle quintile, but only slightly over $40 \%$ for the bottom quintile, with the differences being even starker in previous decades. The reduced importance of salary income at the lower quintiles therefore suggests a natural interpretation for the results in Figure 5: total incomes of the bottom quintiles depend, to a much greater extent than in the rest of the distribution, on sources of income other than earnings.

Table 3 also documents that the largest contributor to total income (approximately 50\%) for those in the bottom quintile of the distribution is the "other income" category, which includes unemployment insurance, Social Security and pension payments, welfare, worker's compensation, and other transfer programs. Even at the second quintile of the distribution, other income accounts for approximately $25 \%$ of total income, whereas this ratio is less than $10 \%$ for the top 2 quintiles. The financial income and business income shares vary much less across the distribution: the share of business income rises from $2 \%$ of total income for the bottom quintile to $5-9 \%$ for the top quintile while financial income falls from a share of $9-12 \%$ at the bottom quintile to approximately $7 \%$ for the top quintile. Figure 3 documented that total transfers to households at the aggregate level fall relatively little on impact after monetary policy shocks and eventually rise. Because lower income households rely more on this source of income than on wage income relative to other households, this mitigates the decline in their total income. In addition, households in the bottom of the income distribution receive a larger share of their income from financial assets. Income from this source rises significantly after monetary policy shocks, again mitigating the effects of declining labor income. Thus, the difference between the response of labor income and total income for lower-income households reflects a composition of income shares which relies less on salary than more affluent households.

This feature of the data is notable for two reasons. First, it illustrates that while the response of labor earnings to monetary policy shocks is symmetric (rising earnings for upper end of the distribution, falling at the lower end), the same is not true for total income. In the case of the latter, the increase in inequality primarily reflects changing incomes at the upper end of the distribution, while incomes at the bottom end differ little from the median as a result of the compensating effect of transfer income. Second, these results suggest that the response of income inequality would likely be even more pronounced if the top $1 \%$ of the income distribution were included. This is because the source of income for the top $1 \%$ is quite different from that of other groups. The CBO (2011) reports that the top 1\% received only 40-50\% of their total non-capital gain income from labor earnings between 1980 and 2007 
while financial income and business income accounted for approximately 30\% and 20\% respectively. Because financial income rises persistently while business income declines only briefly after contractionary monetary shocks, and because their labor earnings are likely to rise at least as much as the $90^{\text {th }}$ percentile, one can reasonably speculate that the total income of the top $1 \%$ would rise by more than most of the households in the CEX. ${ }^{9}$ Thus, our results likely provide a lower bound on the effects of monetary policy shocks on income inequality.

Turning to the responses of consumption by percentile, the results closely mirror those for labor earnings inequality, with the main difference being that the differential behavior between highconsumption and low-consumption households is apparent much earlier than with respect to labor earnings. Most striking, however, is the fact that the long-run responses of consumption percentiles are almost identical to those found for earnings. For example, labor income at the $90^{\text {th }}$ percentile rises by $4 \%$ as does consumption at the $90^{\text {th }}$ percentile. Labor income at the $10^{\text {th }}$ percentile falls by $5 \%$ while consumption at the $10^{\text {th }}$ percentile falls $6 \%$. Results for the $25^{\text {th }}, 50^{\text {th }}$ and $75^{\text {th }}$ percentiles of salary and consumption are all also remarkably close to one another.

Finally, responses of expenditures by percentiles similarly point to substantial heterogeneity in household responses to monetary shocks. The most striking result here is the very large increase in expenditures by those at the $90^{\text {th }}$ percentile of the expenditure distribution relative to others. The magnitude of this increase dwarfs changes in income or earnings and likely explains the fact observed in Figure 4 that expenditure inequality rises so significantly and persistently after monetary policy shocks. One potential explanation for this, in the same spirit as for the behavior of total income of low-income households, could be that high income households (the $90^{\text {th }}$ percentile) have much higher expenditures or a different composition of expenditures than other households. Table 4 therefore provides a decomposition of consumption and expenditures by households across quintiles, ranked by consumption of non-durables and services each quarter, as well as information about their relative expenditures on interest-sensitive expenditures. ${ }^{10}$ While households in the upper end of the distribution consume relatively more durables and devote more of their spending to interest-sensitive expenditures like mortgage payments and auto purchases, the differences across quintiles are small. Furthermore, the ratio of spending on expenditures to consumption of non-durables and services is not rising. We constructed impulse responses of average spending for each of these categories for different quintiles, but found no evidence that households in the upper end of the distribution increased their expenditures more than other

\footnotetext{
${ }^{9}$ Parker and Vissing-Jorgensen (2009) document using the tax return data of Piketty and Saez (2003) that labor earnings of the top 1 percent of the income distribution are more exposed to aggregate fluctuations than other segments of the income distribution.

${ }^{10}$ Interest-sensitive expenditures are defined as mortgage payments, purchases of automobiles, spending on education, spending on repairing houses and other real estate, and durable consumption goods.
} 
households after contractionary shocks. Hence, the greater response of expenditures for those at the $90^{\text {th }}$ percentile of the expenditure distribution after monetary policy shocks cannot be explained via composition of spending across quintiles.

\subsection{Distributional Mobility after Monetary Policy Shocks}

A potential caveat to the responses of specific percentiles of income and consumption distributions to monetary policy shocks is that it is not clear to what extent households are moving across the distribution. To assess mobility across the distribution, we construct time-varying quarterly transition probabilities for each quintile of the consumption distribution. These are defined as the fraction of consumers within each quintile who, in the next quarter, end up in another quintile. Figure 6 plots the time-varying transition frequencies of households staying within the same quintile of the consumption distribution from 1980Q1 until 2008Q4. One notable feature of these time series is that mobility has declined over time for each quintile other than the bottom one. For example, for the middle quintile, the frequency of remaining within that quintile from one quarter to the next has gone from approximately 35\% in 1980 to nearly $45 \%$ in 2008. Furthermore, mobility at the bottom end of the distribution is limited: the frequency at which people in the lowest quintile move to the middle quintile or above has been approximately $5 \%$ each quarter over this time period.

To assess whether monetary policy shocks have significant effects on these transition frequencies, we estimate equation (2) in levels for each series using the squared monetary policy innovations. The latter enable us to identify whether monetary policy shocks, be they positive or negative, lead to increased movements across the distribution. We present impulse responses in the right column of Figure 6. One finding is that there is little persistence in the effects of monetary policy shocks on transition probabilities: after two years, almost none of the estimates are different from zero. A second finding is that monetary policy shocks cause some increased movement within the distribution: the frequency of households remaining within the same quintile declines for all quintiles. These results therefore suggest one reason why the impulse responses for different percentiles of the total income and labor earnings distribution appear so volatile over the first two years: there is likely significant movement within the distribution in the quarters immediately following monetary policy shocks. However, as this increased mobility fades after two years, the responses of the percentiles converge to more stable outcomes. Consistent with this, the responses for percentiles of the expenditures and consumption distributions, which control for composition effects, are much more stable through the first two years of impulse responses than are those of the earnings and income distributions. 


\subsection{How Important Is The Contribution of Monetary Policy Shocks to Inequality?}

In this section, we consider the extent to which monetary policy shocks can account for the dynamics of income and consumption inequality in the U.S. That is, whereas the previous section focused on characterizing whether monetary policy shocks affect inequality, we now turn to the question of assessing the economic importance of this relationship. We do so in two ways. First, we consider the share of the variance in inequality which can be accounted for by monetary policy shocks over this time period. Second, we assess the historical contribution of monetary policy shocks to actual dynamics of U.S. economic inequality.

The fraction of the variance in inequality at different horizons which can be accounted for by monetary policy shocks can be recovered directly from estimates of equation (2). This measure therefore provides one metric of the extent to which monetary policy shocks are quantitatively important in driving inequality dynamics. The results from the variance decompositions, using Gini coefficients, crosssectional standard deviations and $90^{\text {th }}-10^{\text {th }}$ percentiles for inequality, are presented in Figure 7 for total income, labor earnings, total expenditures, and consumption inequality. We present the one-standard confidence intervals of the variance decompositions, based on the distribution of coefficient estimates in (2), as well as the median estimate. The results point to relatively large contributions of monetary policy shocks to inequality dynamics: most of the estimates are between $10 \%$ and $20 \%$. While the exact values differ across inequality measures, these results are consistent with monetary policy shocks playing a nontrivial role in accounting for inequality dynamics in the U.S. For comparison, Appendix Figure 5 plots equivalent variance decompositions for macroeconomic variables over the same time period. With the exception of short-term interest rates and financial income, the contribution of monetary policy shocks to the variance of these variables is also in the $10-20 \%$ range for most forecasting horizons. Thus, the contribution of monetary policy to inequality dynamics is in line with its effects on other macroeconomic variables.

As a second way to assess whether the impulse responses of inequality are economically significant, we consider the extent to which monetary policy shocks since 1980 can account for the historical variation in U.S. income and consumption inequality. To do so, we use the predicted changes in income, salary, expenditure and consumption inequality due to monetary policy shocks from our estimates of equation (2), accumulate them over time and compare them to the actual evolution of inequality measures. We normalize both the predicted and actual series by the trend growth rate of each historical inequality measure to avoid assigning trend growth rates from estimated constants in equation (2) as a contribution of monetary policy shocks. In addition, we average both actual and predicted variables over the previous and subsequent quarter values. This is done to downplay very high-frequency 
variation in inequality measures and to emphasize business cycle variation in inequality. Both the detrending and the averaging are done after the estimation.

Figure 8 presents the results using the cross-sectional standard deviation measures of inequality, with other measures yielding qualitatively similar results. First, monetary policy shocks appear to account for very little of the variation in income, earnings and expenditure inequality until the mid-1990s, with the exception of income inequality for which some of the higher frequency variation in the very early 1980s is consistent with movements induced by monetary policy shocks. Second, monetary policy shocks can account for some of the gradual changes in income and earnings inequality, particularly since the mid-1990s, including the gradual reversion to trend that occurred until 2004, the increase in income and earnings inequality in 2005-2006 during which monetary policy shocks were systematically contractionary, as well as the decline in income and earnings inequality lasting into 2008 while monetary policy shocks were distinctly expansionary. The results are even more striking with consumption inequality: monetary policy shocks account for many of the short-lived deviations from trend in the 1980s and can almost fully account for the behavior of consumption inequality since 2000. Interestingly, monetary policy shocks account for very little of the variation in expenditure inequality over this time period, with the exception of the decline since 2005. For the rest of the sample, there is very little correlation between actual movements in expenditure inequality and predicted changes due to monetary policy shocks.

\section{Wealth Redistribution in Response to Monetary Policy Shocks}

While the previous section documented heterogeneity in labor income responses to monetary policy shocks, as well as heterogeneity in sources of income across individuals, discussion of the distributional effects of monetary policy actions frequently focuses on three additional channels. First, if households hold different portfolios and some financial assets are more protected against inflation surprises than others, then monetary policy actions can, via their effects on inflation, cause a reallocation of wealth across agents, as emphasized in Erosa and Ventura (2002) and Albanesi (2007). A second redistributive channel stems from segmented financial markets: if some agents frequently trade in financial markets and are affected by changes in the money supply prior to other agents who are less involved in financial markets as in Ledoit (2009) and Williamson (2009), then contractionary monetary policy shocks should redistribute wealth from those connected to the markets toward the unconnected agents. If those agents which participate actively in financial trades have higher income and consumption than unconnected agents on average, then consumption inequality should fall after contractionary monetary policy shocks. Unfortunately, the CEX does not include reliable data on the cash holdings of households nor does it include information that would allow us to identify which households are most connected to financial 
markets, such as those working for the financial industry. However, to the extent that both channels point toward contractionary monetary policy shocks lowering consumption inequality, the fact that our baseline results go precisely in the opposite direction suggests that these channels, if present, must be significantly weaker than the labor earnings channel.

In addition, because monetary policy actions alter real interest rates in the short run, they will have redistributive effects on savers and borrowers as in Doepke and Schneider (2006): since contractionary policy shocks represent a transfer from borrowers (low net-worth) to savers (high networth), one might expect to see disproportionate increases in the expenditures of borrowers. While the CEX does not include reliable data on the net wealth position of households, we can still assess this channel by restricting our attention to households with those characteristics identified by Doepke and Schneider (2006) as being closely associated with high net-worth and low net-worth households. Specifically, they argue that the main losers from inflation are "rich, old households" while the main winners are "young, middle-class households with fixed-rate mortgage debt." In the context of the CEX, we therefore restrict the sample to two groups: 1) low net-worth households are defined as aged 30-40 year-old white households with a male head in the household, no financial income, and positive mortgage payments, 2) high net-worth households are defined as aged 55-65 years white households with a male head in the household, positive financial income, and no mortgage payments. We restrict the first two categories to be white households with a male head in the household to limit the possible sources of differences between the two categories without unduly restricting the number of households in each group (as would be the case, for example, if we imposed restrictions on education levels).

For each set of households, we then construct measures of mean (log) income and expenditures as well as subcategories of each. Impulse responses for each group are constructed using equation (2) as before. The results, plotted in Figure 9, support the redistribution of nominal wealth effect in generating heterogeneity in consumption and total expenditures. While there is little evidence that either labor earnings or total income responses differ across the two groups, the high net-worth households display increases in consumption and total expenditures relative to low net-worth households, consistent with a redistributive effect of monetary policy. In addition, because high net-worth households are, on average, in the upper end of the income and consumption distributions, this channel will tend to reinforce the positive effects of contractionary monetary policy shocks on income and consumption inequality.

\section{Permanent Changes in Monetary Policy}

In assessing the effects of monetary policy shocks on inequality, we have followed the approach of Romer and Romer (2004) because their identification procedure has a number of advantages over previous attempts to do so. First, the use of changes in the FFR target decided upon specifically at FOMC 
meetings mitigates the possibility of including day-to-day changes in the FFR which have little to do with monetary policy. Second, policy changes are purged of anticipatory effects by controlling for the realtime forecasts of the staff of the Federal Reserve. The resulting shocks should identify changes in policy which are not taken in response to economic conditions. As emphasized by $R R$, their procedure is not designed to characterize the reaction function of the Fed and therefore the identified innovations reflect a number of potential sources: the evolution of the Fed's operating procedures, policymakers' evolving beliefs about the workings of the economy, variation in the Fed's objectives, political pressures, and responses to other factors. Some of these changes could be interpreted as innovations to the central bank's policy rule (i.e. its systematic behavior) -for example if a new Chairman dislikes inflation more than a previous one- while others would more appropriately be characterized as transitory deviations from a policy rule (for example, political pressures at the time of an election). RR deliberately do not attempt to separate out these different sources to maintain as much variation in the shocks, but a caveat to this is that different sources of shocks may yield very different economic responses. In particular, one might expect permanent changes in monetary policy to have more pronounced effects than transitory changes. And if different forms of monetary policy actions affect inequality differently, then using a composite shock measure such as that of RR may understate the effects of monetary policy on inequality.

As a result, we want to assess whether similar qualitative results obtain using a narrower but more persistent type of monetary policy action: changes in the Federal Reserve's target rate of inflation. Because of the inability to directly observe the historical inflation target of the Federal Reserve, we consider two different estimates of this measure. First, following Coibion and Gorodnichenko (2011), we posit a reaction function for the central bank:

$$
\begin{array}{r}
i_{t}=\left(1-\rho_{1, t}-\rho_{2, t}\right)\left[F_{t} r r_{t}^{n}+\varphi_{\pi, t}\left(F_{t} \pi_{t+1}-\bar{\pi}_{t}\right)+\varphi_{g y, t}\left(F_{t} g y_{t}-\overline{g y}\right)+\varphi_{x, t} x_{t}\right] \\
+\rho_{1, t} i_{t-1}+\rho_{2, t} i_{t-2}+v_{t}
\end{array}
$$

according to which the central bank moves interest rates with its perception of the natural rate of interest $F_{t} r r_{t}^{n}$, and also responds to deviations of expected inflation $F_{t} \pi_{t+1}$ from its potentially time-varying target $\bar{\pi}_{t}$, deviations of expected output growth from its target $\left(F_{t} g y_{t}-\overline{g y}\right)$, and the output gap $\left(x_{t}\right)$. In addition to allowing for time variation in the intercept, we allow for variation in the target level of inflation, in the response coefficients to macroeconomic conditions, and in the degree of interestsmoothing. Each time-varying coefficient is assumed to follow a random walk process as in Boivin (2006). We estimate the coefficients of this reaction function as in Kozicki and Tinsley (2009) and 
Coibion and Gorodnichenko (2011, CG henceforth) using data from 1969 to 2008 at the frequency of FOMC meetings using real-time forecasts of inflation, output growth and the output gap. ${ }^{11}$

As an alternative measure, we also use the inflation target estimated by Ireland (2006). Ireland uses an otherwise standard small-scale New Keynesian model with a Taylor rule in which the target rate of inflation rate varies over time. He then estimates the parameters of the model by maximum-likelihood methods using data on output, prices, and interest rates, from which he recovers the implied time path of the Fed's target rate of inflation. Thus, whereas our first measure of target inflation comes from singleequation of a Taylor rule with time-varying coefficients in real-time Greenbook forecasts, Ireland's approach is the polar opposite: estimation of the entire structural model using final data for macroeconomic aggregates and no real-time forecasts.

The two estimates of the Fed's target rate of inflation are plotted in Figure 10. Both approaches point toward rising inflation targets over the 1970s, peaking at approximately $8 \%$. The two measures also pick up rapid declines in target inflation in the early 1980s, corresponding to the Volcker disinflation, and a prolonged subsequent decline in the target inflation rate over the course of the 1990s and 2000s, with the target rate of inflation reaching $2 \%$ in 2005 in both cases. At the same time, a number of qualitative differences are present: Ireland's measure points to a rapid increase in the inflation target starting around 1973, reaching $8 \%$ in late 1974 before declining to $6 \%$ in 1975 . In contrast, the CG measure points to only a gradual increase in the inflation target during this time period. Second, while both measures reach maximum values of 8\% prior to the Volcker disinflation, the Ireland measure begins to decline in 1981 while the CG measure continues to rise until the end of 1982, at which point it drops much more abruptly: $3 \%$ points over the course of just a few months.

To assess the effects of changes in target inflation rates on inequality, we again estimate equation (2) for consumption and income inequality measures but now using either measure of shocks to the inflation target rather than RR shocks. The results for cross-sectional standard deviations, for a 1\% point decrease in the inflation target, are plotted in the top row of Figure $11 .{ }^{12}$ First, both inflation target measures yield statistically significant responses in which disinflations raise long-run levels of both income and consumption inequality, with only the response of total income inequality to CG shocks being

\footnotetext{
${ }^{11}$ Because Greenbook forecasts are only available until the end of 2006, we use consensus forecasts from Blue Chip Economic Indicators for FOMC meetings in 2007 and 2008. The latter do not include forecasts of the output gap but do include unemployment forecasts. We generate forecasts of the output gap for 2007 and 2008 by first constructing historical real-time Greenbook forecasts of the unemployment gap (the difference between GB forecasts of UE and GB estimates of the NAIRU) from 1997 to 2006, estimate the historical (linear) relationship between GB forecasts of the output gap and the unemployment gap, then use this version of Okun's Law embedded in GB forecasts to convert the unemployment gaps in BCEI forecasts (the consensus forecast of unemployment minus the real-time estimates of the NAIRU from the Survey of Professional Forecasters) into output gap forecasts. See Coibion and Gorodnichenko (2011) for details on constructing the dynamics of the real interest rate.

${ }^{12}$ Results for other measures are similar and available upon request.
} 
marginally significant. Second, the estimated effects are quantitatively similar across income and consumption measures, with inequality of each type rising approximately $2 \%$. Finally, while both the short-run and long-run dynamics are similar for consumption and expenditure inequality across the two measures, the short-run dynamics in income and earnings inequality differ more depending on which measure is used.

The middle row of Figure 11 presents the contribution of shocks to the inflation target to the forecast error variance of each inequality measure. These are around $10-20 \%$ at different horizons, in line with the baseline estimates using RR shocks, and even higher in the case of consumption. This suggests that inflation target shocks, by themselves, can account for a significant proportion of the variation in inequality measures. The bottom row of Figure 11 then presents the historical contribution of target inflation shocks to inequality. In the case of consumption and expenditure inequality, both measures of target inflation point to very important contributions of monetary policy: the disinflation of the early 1980s generates a very large increase in these forms of inequality which can readily account for the persistently high levels of inequality (relative to trend) in the mid-1980s and 1990s. In the case of income and earnings inequality, Ireland's measure of target inflation shocks can fully account for the large increase in these forms of inequality in the early 1980s and its persistence. In contrast, the CG measure accounts for only a fraction of the variation in income and earnings inequality, likely because the dramatic decline in target inflation in the CG measure occurs too late to explain the early 1980s increase in income inequality. ${ }^{13}$

The finding that persistent disinflations have raised income inequality in the U.S. is at odds with a number of papers documenting a positive relationship between inequality and inflation across countries (e.g. Easterly and Fischer 2001, Albanesi 2007, Romer and Romer 1998). On the one hand, because these papers primarily focus on cross-country correlations over extended periods of time, the positive correlation could reflect confounding factors. For example, countries with greater inequality could be more liable to adopt populist policies including higher inflation. In contrast, we focus on the conditional response of inequality to disinflationary policies, thereby mitigating concerns about other factors driving the correlation. Alternatively, the apparent conflict between our results and these prior papers could reflect our focus on U.S. economic conditions since 1980 rather than cross-country

\footnotetext{
${ }^{13}$ We also considered how inflation target shocks affect different sides of the distribution. Results are in Appendix Figure 6. For consumption, both measures indicate that the low end of the distribution fares no worse than the median, but the high-end of the distribution fares better. For expenditures, both measures yield the result that the bottom end of the distribution falls further below the median, but deliver conflicting results for the upper end of the distribution. For total income and labor earnings inequality however, both measures of the inflation target yield the finding that the source of the rise in both forms of inequality after contractionary shocks is a relative decline in the incomes and labor earnings of the $10^{\text {th }}$ percentile relative to the median, whereas the $90^{\text {th }}$ percentiles fare little better than the median. This suggests that, unlike using the broader measure of RR shocks, households in the bottom half of the income distribution bear a disproportionate share of the effects of disinflationary policies on income.
} 
comparisons. For example, one might expect the strength of the portfolio channel -in which low-income households hold relatively more currency and are therefore more susceptible to inflation- to be stronger in countries with less developed financial systems than the U.S. Similarly, cross-country heterogeneity in labor market institutions, transfer systems, and skill distributions, among many other factors, would affect the relative strength of the different channels through which (dis)inflationary policies affect income and consumption distributions. Hence, one should be wary of drawing broad conclusions about whether higher inflation necessarily increases or decreases economic inequality across different countries or time periods, particularly in the presence of other significant institutional changes.

\section{Conclusion}

Recent events have brought both monetary policy and economic inequality to the forefront of policy issues. At odds with the common wisdom of mainstream macroeconomists, a tight link between the two has been suggested by a number of people, ranging widely across the political spectrum from Ron Paul and Austrian economists to Post-Keynesians such as James Galbraith. But while they agree on a causal link running from monetary policy actions to rising inequality in the U.S., the suggested mechanisms vary. Ron Paul and the Austrians emphasize inflationary surprises lowering real wages in the presence of sticky prices and thereby raising profits, leading to a reallocation of income from workers to capitalists. In contrast, post-Keynesians emphasize the disinflationary policies of the Federal Reserve and their disproportionate effects on employment and wages of those at the bottom end of the income distribution.

We shed new light on this question by assessing the effects of monetary policy shocks on consumption and income inequality in the U.S. Contractionary monetary policy shocks appear to have significant long-run effects on inequality, leading to higher levels of income, labor earnings, consumption and total expenditures inequality across households, in direct contrast to the directionality advocated by Ron Paul and Austrian economists. Furthermore, while monetary policy shocks cannot account for the trend increase in income inequality since the early 1980s, they appear to have nonetheless played a significant role in cyclical fluctuations in inequality and some of the longer-run movements around the trends. This is particularly true for consumption inequality, which is likely the most relevant metric from a policy point of view, and expenditure inequality after changes in the target inflation rate. To the extent that distributional considerations may have first-order welfare effects, our results point to a need for models with heterogeneity across households which are suitable for monetary policy analysis. While heterogeneous agent models with incomplete insurance markets have become increasingly common in the macroeconomics literature, little effort has, to the best of our knowledge, yet been devoted to considering their implications for monetary policy. In light of the empirical evidence pointing to non-trivial effects of 
monetary policy on economic inequality, this seems like an avenue worth developing further in future research.

Specifically, the dynamic responses to monetary policy shocks point toward two key channels that appear to be empirically important. First, monetary policy shocks have effects on labor earnings which vary systematically across the income distribution: labor income rises at the upper end of the distribution and falls at the lower end. Given that monetary policy shocks operate primarily through interest rates, this would suggest that modeling the complementarity/substitutability of capital with different forms of labor (such as skilled or unskilled) could go some way in accounting for these patterns. Alternatively, this heterogeneity could reflect different age profiles and associated labor supply elasticities or complementarities between labor and consumption. Identifying this causal link would be an important step in better understanding the relationship between monetary policy, income inequality, and economic outcomes.

Second, the disproportionate increase in expenditures for those at the upper end of the expenditure distribution relative to income changes suggests the possibility of significant wealth transfers via unexpected changes in interest rates and inflation. We document that the response of consumption and expenditures by high net-worth households is larger than that of low net-worth households in the data, consistent with the redistributive effects in Doepke and Schneider (2006). While the data limitations of the CEX make the identification of high and low net-worth households tentative, our results do suggest that household balance sheets may play an important link in the monetary transmission mechanism. In contrast, while the CEX data do not allow us to directly quantify the portfolio and financial market segmentation redistribution channels, their counterfactual predictions of consumption inequality falling after contractionary monetary policy shocks suggests that these channels, if present, are quantitatively small relative to the other channels linking economic inequality and monetary policy in the U.S.

Finally, the sensitivity of inequality measures to monetary policy actions points to even larger costs of the zero-bound on interest rates than is commonly identified in representative agent models. Nominal interest rates hitting the zero-bound in times when the central bank's systematic response to economic conditions calls for negative rates is conceptually similar to the economy being subject to a prolonged period of contractionary monetary policy shocks. Given that such shocks appear to increase income and consumption inequality, our results suggest that standard representative agent models may significantly understate the welfare costs of zero-bound episodes. 


\section{References}

Aguiar, Mark and Mark Bils, 2011. “Has Consumption Inequality Mirrored Income Inequality?” NBER Working Paper 16807.

Albanesi, Stefania, 2007. "Inflation and inequality,” Journal of Monetary Economics, 54(4) 1088-1114.

Attanasio, O.P. 2003. "Consumption Inequality: What we know and what we can learn from it," Lecture to the Annual Meeting of the Society of Economic Dynamics, New York, June 2002

Attanasio, Orazio, Erich Battistin, and Hidehiko Ichimura Boivin 2006. "What really happened to consumption inequality in the US?” NBER Working Paper 10338.

Attanasio, Orazio, Erik Hurst, and Luigi Pistaferri, 2012. “The Evolution of Income, Consumption and Leisure Inequality in the U.S., 1980-2010.” NBER Working Paper 17982.

Bernanke, Ben S., and Kenneth N. Kuttner. "What Explains the Stock Market's Reaction to Federal Reserve Policy?" Journal of Finance 60(3): 1221-1257, June 2005 ,

Boivin, Jean, 2006. "Has U.S. Monetary Policy Changed? Evidence from Drifting Coefficients and RealTime Data,” Journal of Money, Credit and Banking 38(5), 1149-1173.

Boivin, Jean and Marc P. Giannoni. 2006. “Has Monetary Policy Become More Effective?” Review of Economics and Statistics 88(3), 445-462.

Bound, John and George Johnson, 1992. "Changes in the Structure of Wages in the 1980s: An Evaluation of Alternative Explanations.” American Economic Review 83 (June), 371-392.

Card, David, 2001. "The Effect of Unions on Wage Inequality in the U.S. Labor Market," Industrial and Labor Relations Review 54(2), 296-315.

Carpenter, Seth B. and William M. Rodgers III, 2004. "The Disparate Labor Market Impacts of Monetary Policy,” Journal of Policy Analysis and Management 23(4), 813-830.

Christiano, Lawrence J., Martin Eichenbaum, and Charles L. Evans, 1999. "Monetary policy shocks: What have we learned and to what end?" Handbook of Macroeconomics, in: J. B. Taylor and M. Woodford (ed.), Handbook of Macroeconomics, edition 1, volume 1, chapter 2, pages 65-148 Elsevier.

Christiano, Lawrence, Martin Eichenbaum, and Charles Evans, 2005. "Nominal Rigidities and the Dynamic Effects of a Shock to Monetary Policy,” Journal of Political Economy 113(1), 1-45.

Clarida, Richard, Jordi Galí, and Mark Gertler, 2000. "Monetary Policy Rules and Macroeconomic Stability: Evidence and Some Theory,” Quarterly Journal of Economics 115(1), 147-180.

Cochrane, John H. and Monika Piazzesi, 2002. "The Fed and Interest Rates - A High-Frequency Identification,” American Economic Review 92(2), 90-95.

Coibion, Olivier. 2012. "Are the effects of monetary policy shocks big or small?" forthcoming in the American Economic Journal: Macroeconomics.

Coibion, Olivier and Yuriy Gorodnichenko. 2011. "Monetary Policy, Trend Inflation and the Great Moderation: An Alternative Interpretation,” American Economic Review 101(1), 341-70.

Congressional Budget Office, 2011. "Trends in the Distribution of Household Income Between 1979 and 2007.” http://cbo.gov/sites/default/files/cbofiles/attachments/10-25-HouseholdIncome.pdf

Doepke, Matthias and Martin Schneider, 2006. "Inflation and the Redistribution of Nominal Wealth," Journal of Political Economy 114(6) 1069-1097.

Easterly, William and Stanley Fischer, 2001. "Inflation and the Poor," Journal of Money, Credit and Banking, 33(2) 160-78.

Erosa, Andres and Gustavo Ventura, 2002. “On Inflation as a Regressive Consumption Tax,” Journal of Monetary Economics 49(4) 761-795.

Feenberg, Daniel and Elisabeth Coutts, 1993. “An introduction to the TAXSIM model,” Journal of Policy Analysis and Management 12(1) 189-194

Feenstra, Robert, and Gordon Hanson, 2008. "Global Production Sharing and Rising Inequality: A Survey of Trade and Wages," Handbook of International Trade.

Galbraith, James K., 1998. "With Economic Inequality for All,” The Nation, Sept. 7-14. 
Galbraith, James K., 2007. “The Fed's Real Reaction Function: Monetary Policy, Inflation, Unemployment, Inequality - and Presidential Politics” University of Texas Inequality Project Working Paper 42.

Gali, Jordi. 1999. Technology, Employment and the Business Cycle: Do Technology Shocks Explain Aggregate Fluctuations?” American Economic Review 89(1), 249-271.

Heathcote, Jonathan, Fabrizio Perri, and Gianluca Violante, 2010. "Unequal We Stand: An Empirical Analysis of Economic Inequality in the U.S., 1967-2006.” Review of Economic Dynamics 13(1) 15-51.

Ireland, Peter N., 2006. “Changes in the Federal Reserve’s Inflation Target: Causes and Consequences,” Journal of Money, Credit and Banking 39(8) 1851-1882.

Kilian, Lutz, 2009. "Not All Oil Price Shocks Are Alike: Disentangling Demand and Supply Shocks in the Crude Oil Market," American Economic Review 99(3) 1053-1069.

Kozicki, Sharon and Peter A. Tinsley, 2009. "Perhaps the 1970s FOMC did what it said it did,” Journal of Monetary Economics, 56(6) 842-855.

Krueger, Dirk and Fabrizio Perri, 2005. "Does Income Inequality Lead to Consumption Inequality? Evidence and Theory," Review of Economic Studies 73(1) 163-193.

Krueger, Dirk, Fabrizio Perri, Luigi Pistaferri, and Giovanni L. Violante, 2010. "Cross sectional Facts for Macroeconomists," Review of Economic Dynamics 13(1) 1-14.

Kueng, Lorenz, 2012. "Tax News: Identifying the Household Consumption Response to Tax Expectations Using Municipal Bond Prices,” Working Paper.

Kumhof, M. and Romain Ranciere. 2011. “Inequality, Leverage, and Financial Crises,” IMF Working Paper 10/268.

Ledoit, Olivier. 2009. “The Redistributive Effects of Monetary Policy,” Manuscript.

Newey, Whitney K. and Kenneth D. West, 1987. "A Simple, Positive Semi-definite, Heteroskedasticity and Autocorrelation Consistent Covariance Matrix,” Econometrica 55(3) 703-708.

Pagan, Adrian, 1984. "Econometric Issues in the Analysis of Regressions with Generated Regressors," International Economic Review 25(1) 221-247.

Parker, Jonathan A., 1999. "The Reaction of Household Consumption to Predictable Changes in Social Security Taxes," American Economic Review 89(4).

Parker, Jonathan A. and Annette Vissing-Jorgensen, 2009. "Who Bears Aggregate Fluctuations and How?” American Economic Review 99(2), 399-405.

Piketty, Thomas and Emmanuel Saez, 2003. "Income Inequality in the United States, 1913-1998," Quarterly Journal of Economics 118(1) 1-39.

Rajan, R. 2010. "Fault Lines,” Princeton University Press, Princeton N.J.

Romer, Christina D. and David H. Romer, 1998. "Monetary Policy and the Well-Being of the Poor," in Income Inequality: Issues and Policy Options (Federal Reserve Bank of Kansas City), 159-201.

Romer, Christina D. and David H. Romer, 2004. "A New Measure of Monetary Shocks: Derivation and Implications,” American Economic Review, September 1055-1084.

Romer, Christina D. and David H. Romer, 2010. "The Macroeconomic Effects of Tax Changes: Estimates Based on a New Measure of Fiscal Shocks,” American Economic Review, 100(3), 763801.

Taylor, John. 2007 "Housing and Monetary Policy,” Speech at the Federal Reserve Bank of Kansas City Symposium on Housing, Housing Finance, and Monetary Policy.

Taylor, John B. 1993. "Discretion versus policy rules in practice," Carnegie-Rochester Conference Series on Public Policy 39, pp. 195-214.

Williamson, Stephen D., 2009. “Monetary Policy and Distribution,” Journal of Monetary Economics 55(6), 1038-1053. 
FIGURE 1: INEQUALITY IN TOTAL INCOME, LABOR EARNINGS, EXPENDITURES AND CONSUMPTION IN THE UNITED STATES. Panel A: Cross-Sectional Standard Deviations

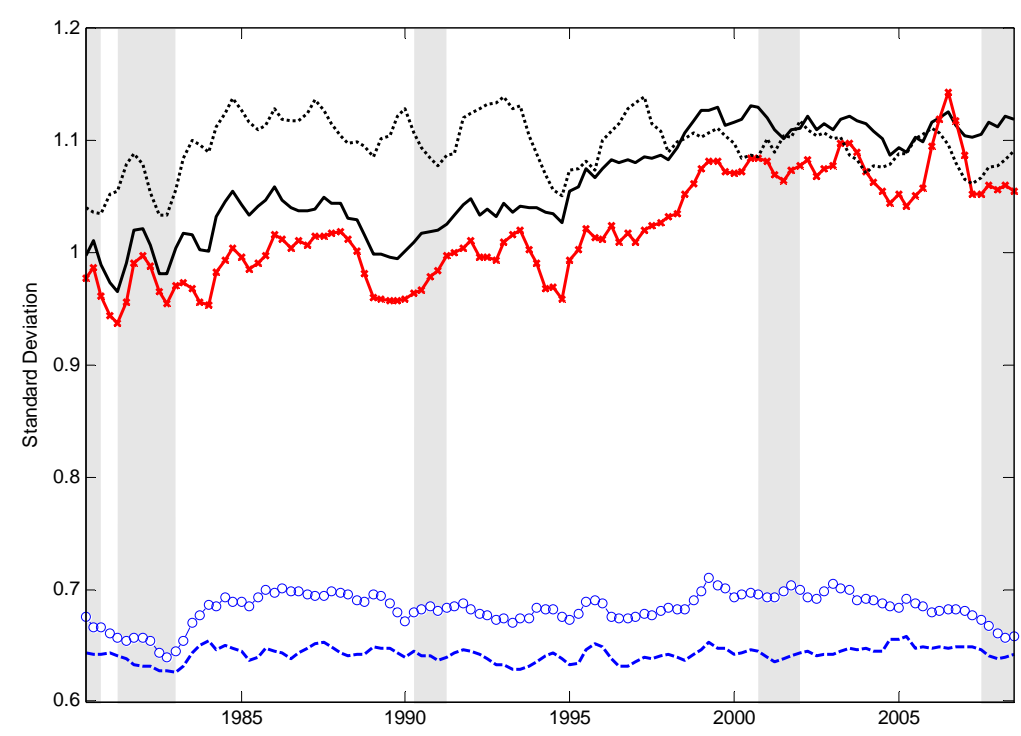

Panel B: Gini Coefficients

Panel C: $90^{\text {th }}-10^{\text {th }}$ Percentiles

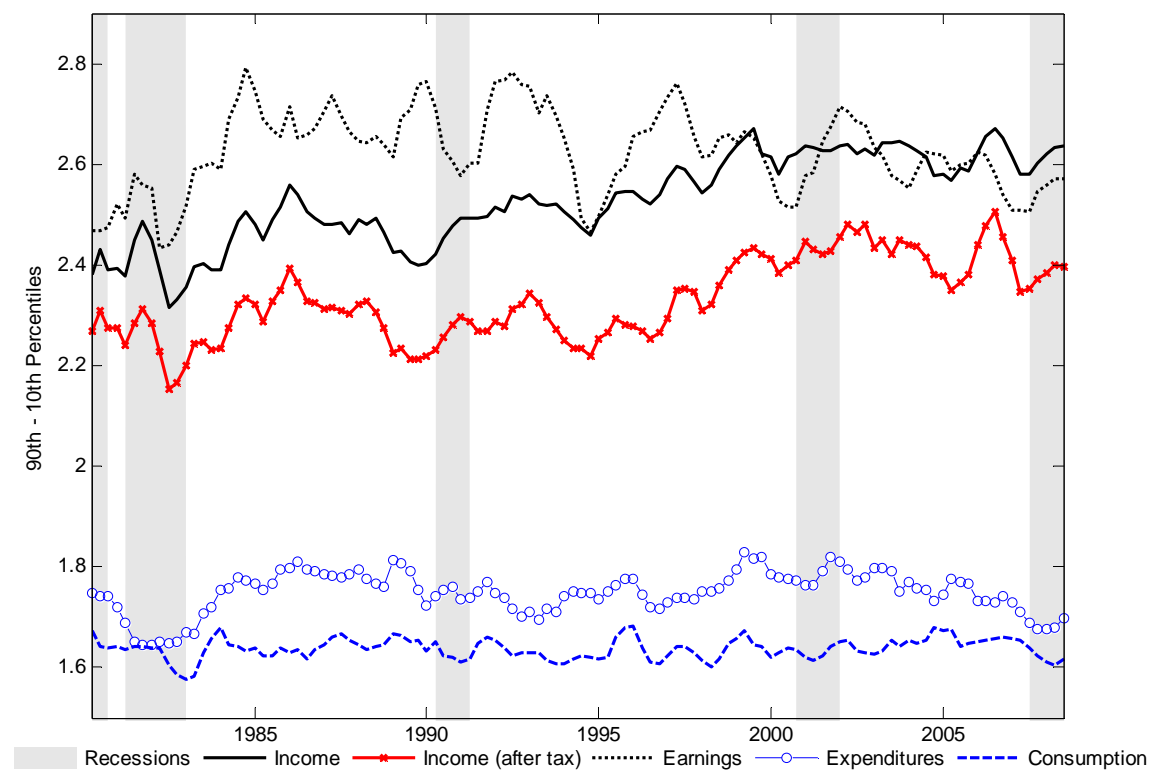

Note: All inequality measures are averaged over previous and subsequent quarters. See section 2.3 in the text. 
FiguRE 2: MONETARY POLICY SHOCKS

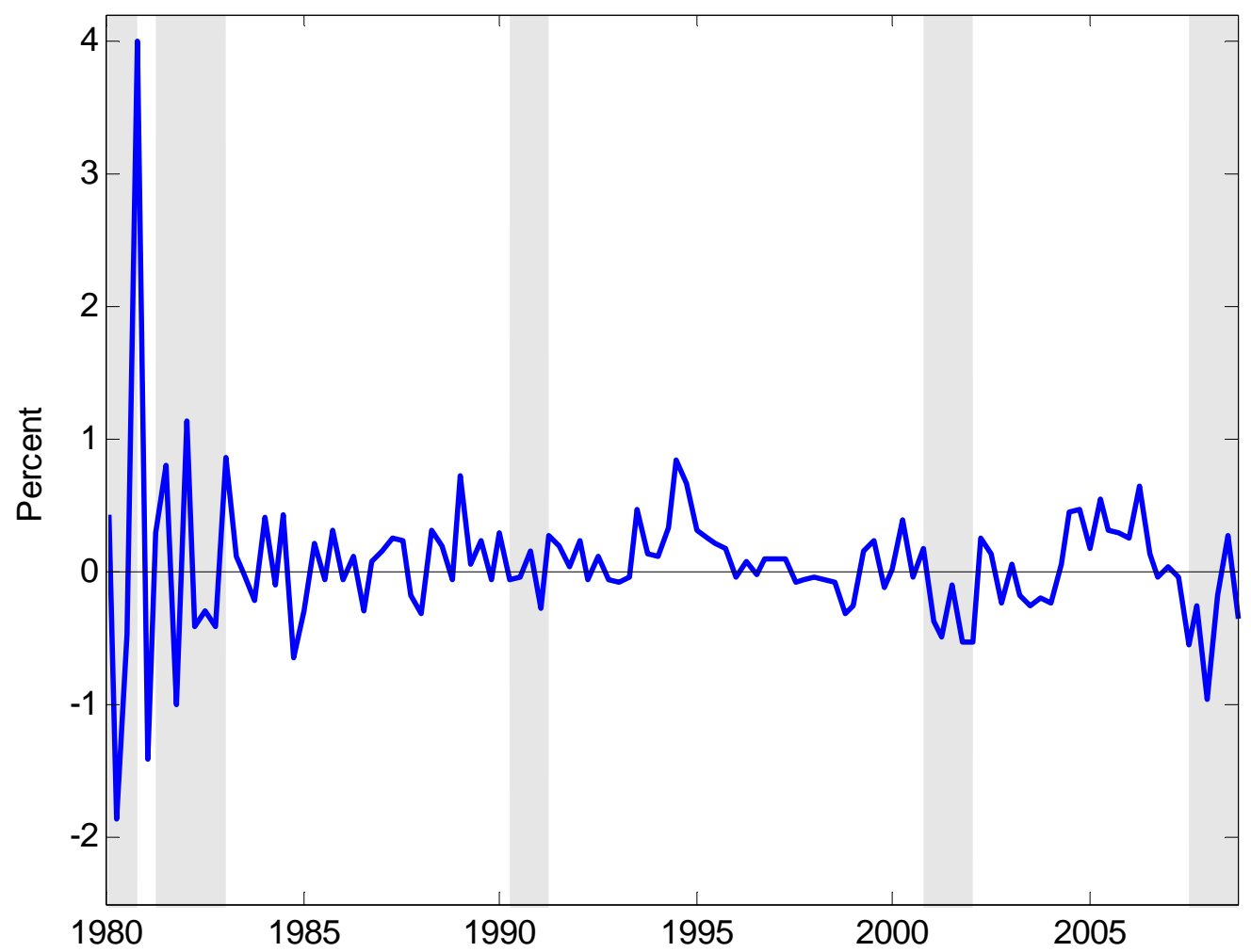

Note: The figure plots the quarterly sum of monetary policy shocks as identified in Romer and Romer (2004). See section 3.1 for details. 


\section{Figure 3: EFFECTS OF MONETARY POLICY SHOCKS ON MACROECONOMIC VARIABLES}
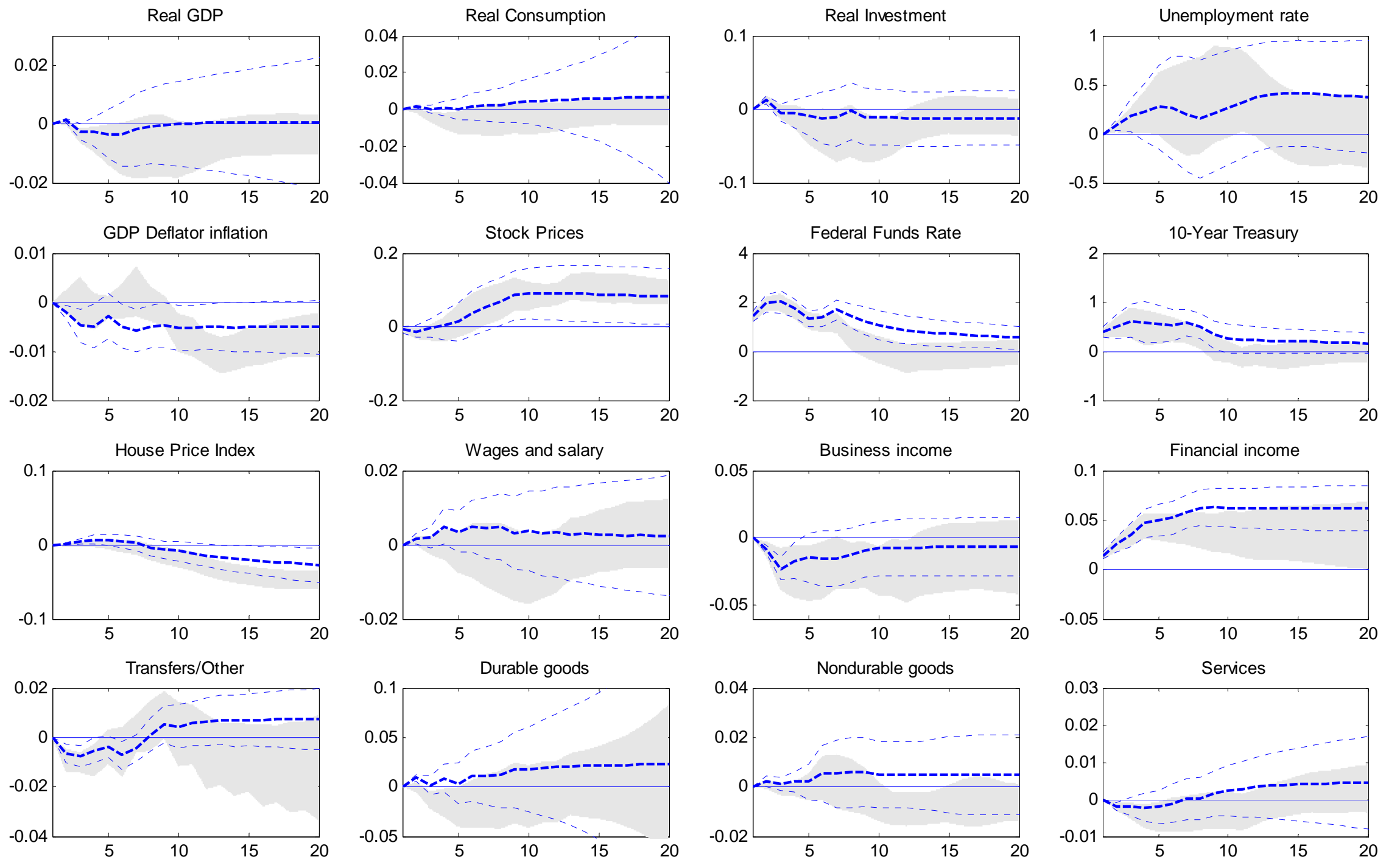

Note: The figure presents impulse responses of macroeconomic variables to 100 b.p. monetary policy shocks. The grey shaded areas indicate one-standard deviation confidence intervals using data from 1969Q1 until 2008Q4. The light dashed lines are one standard deviation confidence intervals using data since 1980Q1, with the bold dashed line indicating point estimates. See section 3.1 for details. 
FiguRE 4: RESPONSE OF ECONOMIC INEQUALITY TO A CONTRACTIONARY MONETARY POLICY SHOCK
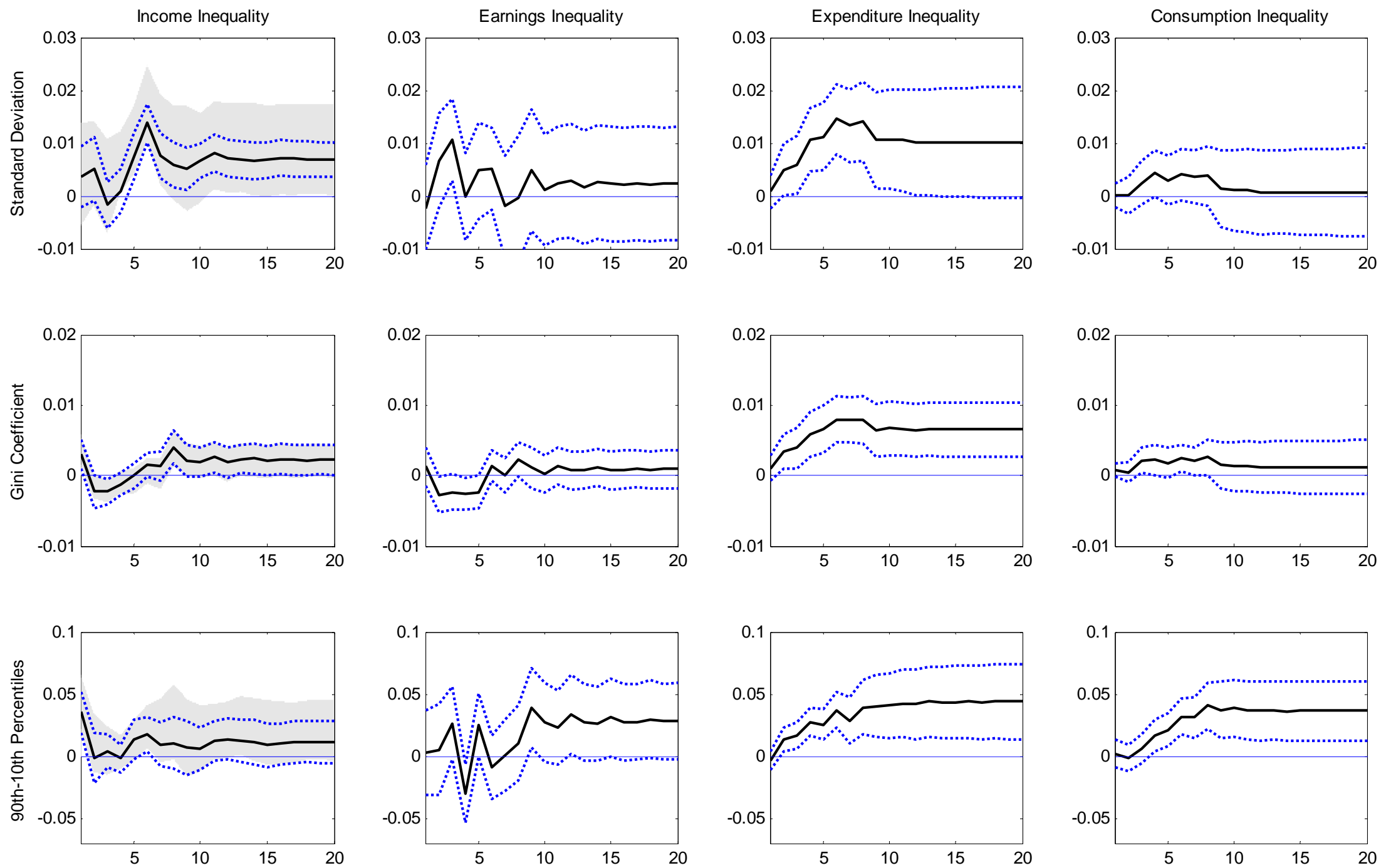

Notes: The figure plots impulse responses (solid line) and one standard deviation confidence intervals (dotted lines) of inequality measures for total income (first column), salary income (second column), total expenditures (third column), and consumption (fourth column) in response to a 1 percentage point (100 b.p.) contractionary monetary policy shock. In the first column, the grey shaded areas are one standard deviation confidence intervals for the response of after-tax income inequality. Inequality is measured using the cross-sectional standard deviation (first row), Gini coefficient (second row), and the difference between the $90^{\text {th }}$ and $10^{\text {th }}$ percentiles of the cross-sectional distribution. Impulse responses are at the quarterly frequency using data from 1980Q1:2008Q4. See section 3.2 for details. 
Figure 5: Distributional EfFECTS OF CONTRACTIONARY MONETARy POLICY SHOCK By PERCENTILE S
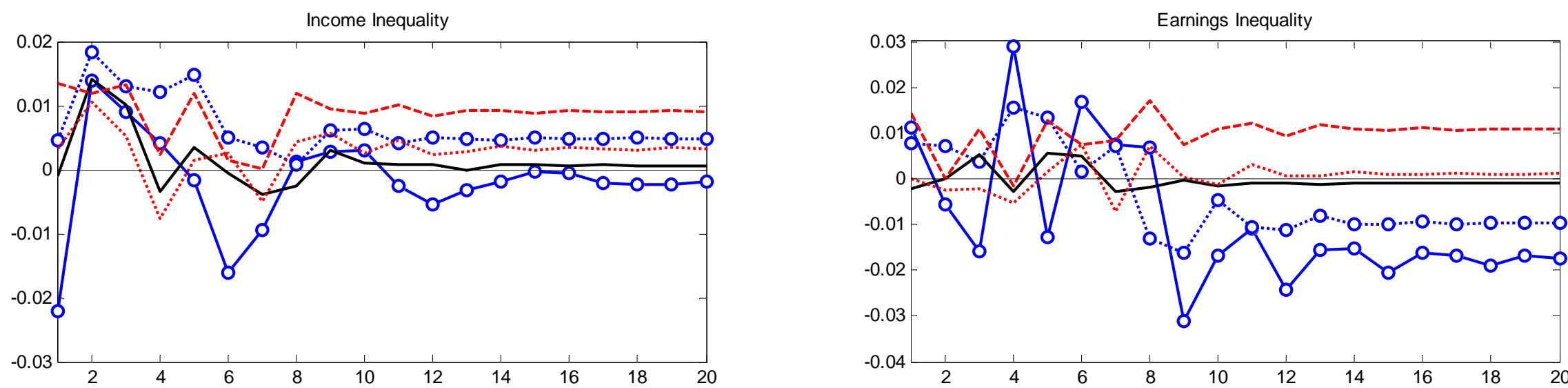

一- P10 …..... P25 — P50 …...... P75 ----- P90
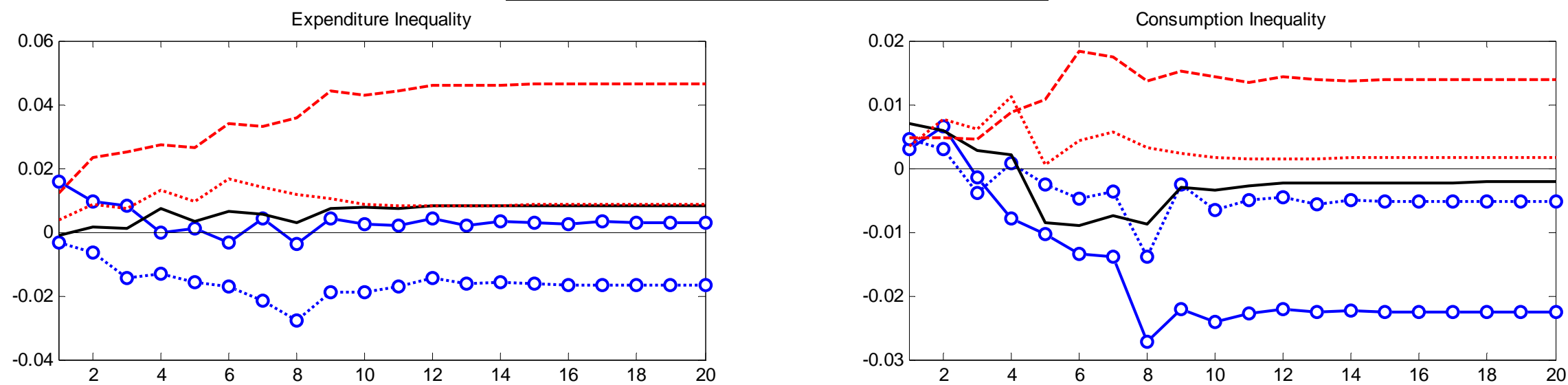

Notes: The figure plots the responses of each percentile of the income, salary, expenditure and consumption distributions of households in the CEX to a 1 percentage point (100 b.p.) contractionary monetary policy shock using data from 1980Q1-2008Q4. P10 corresponds to the $10^{\text {th }}$ (lowest) percentile of each distribution and equivalently for P25, P50, P75 and P90. See section 3.3 for details. 
Figure 6: Time-VARYing PROBABILITIES OF TRANSITIONING BETWEEN CONSUMPTION QUiNTILES

Time series
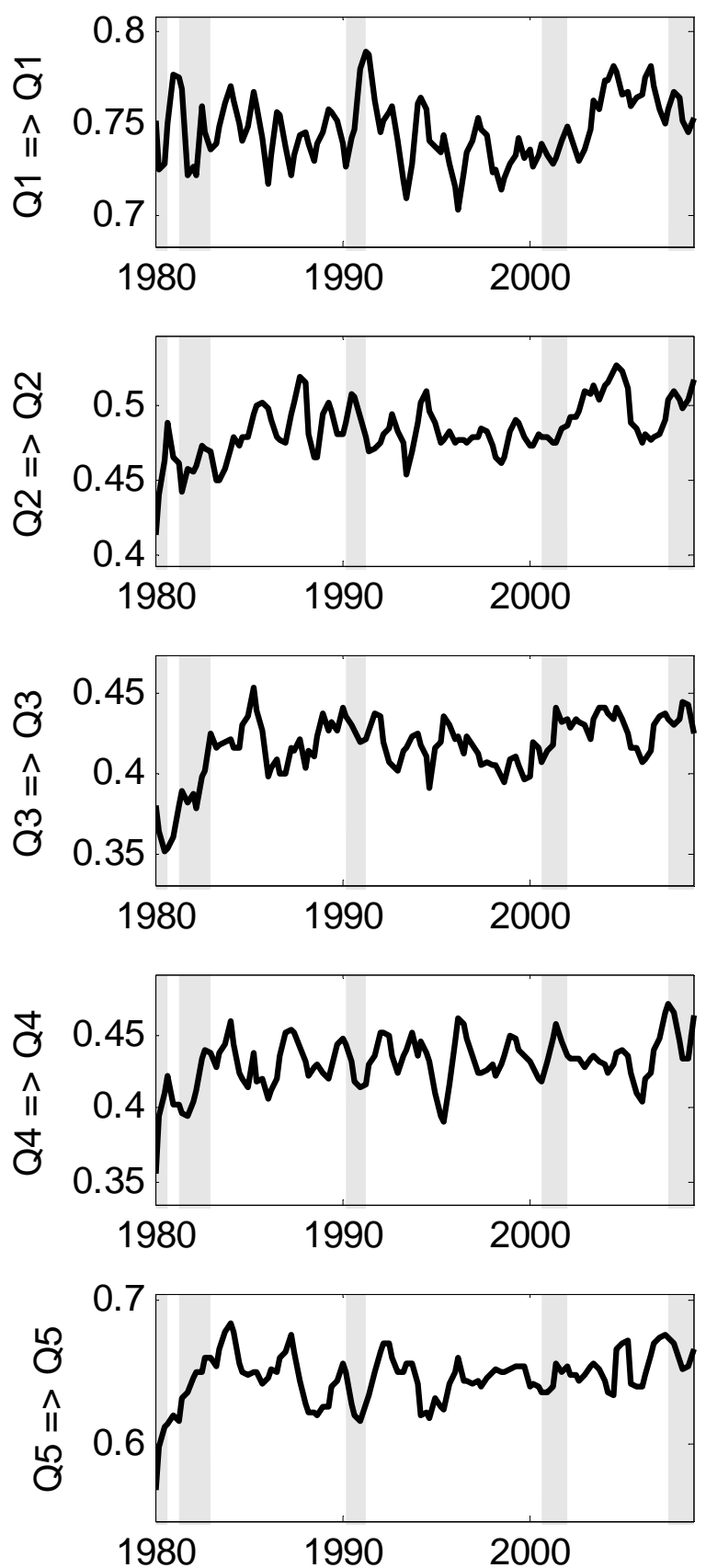

Impulse response
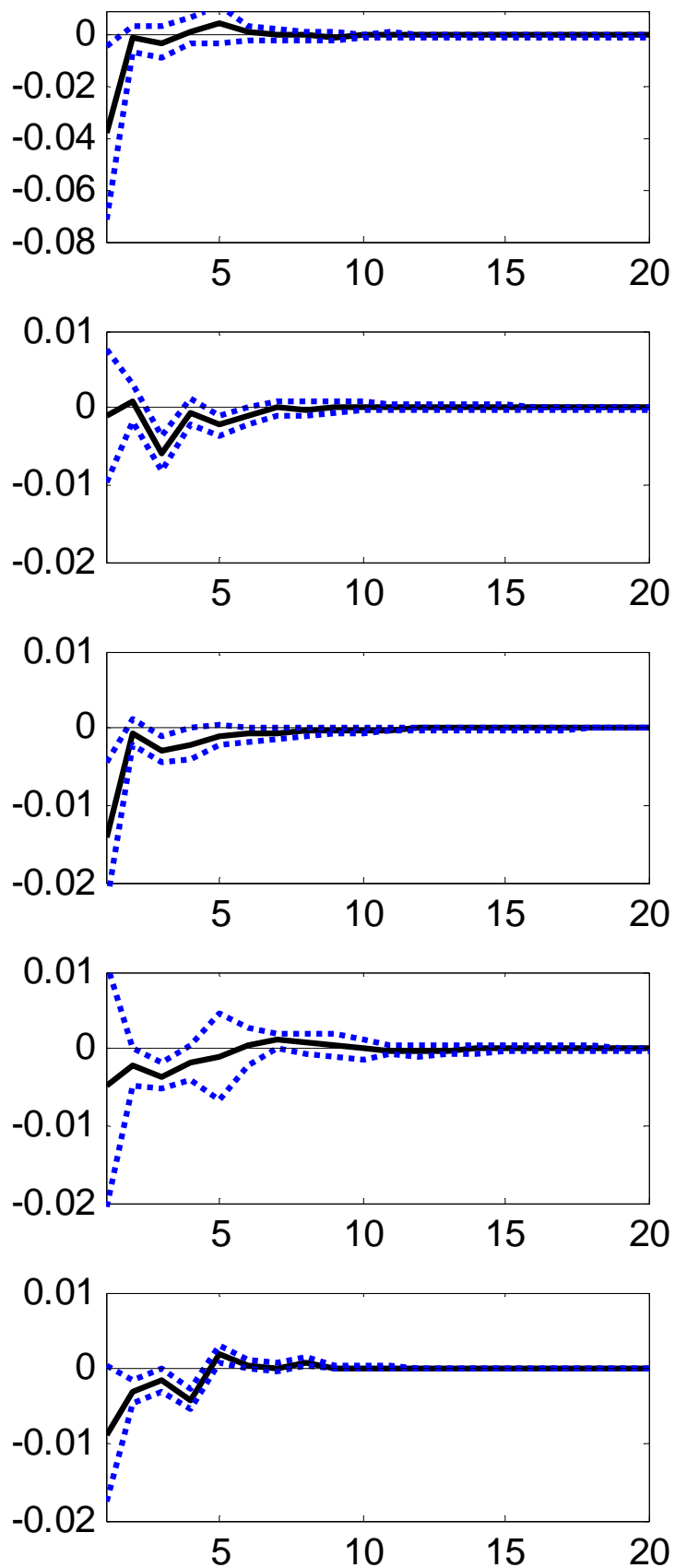

Note: The left column of the figure plots the frequency of households staying in the same quintile of the consumption (of non-durables and services) distribution from one quarter to the next. The right column shows the response of these probabilities to a squared monetary policy shock, with one standard deviation confidence intervals given by dotted lines. Grey shaded areas are U.S. recessions. See section 3.4 for details. 
FIGURE 7: CONTRIBUTION OF MONETARY POLICY SHOCKS TO FORECAST ERROR VARIANCE OF INEQUALITY
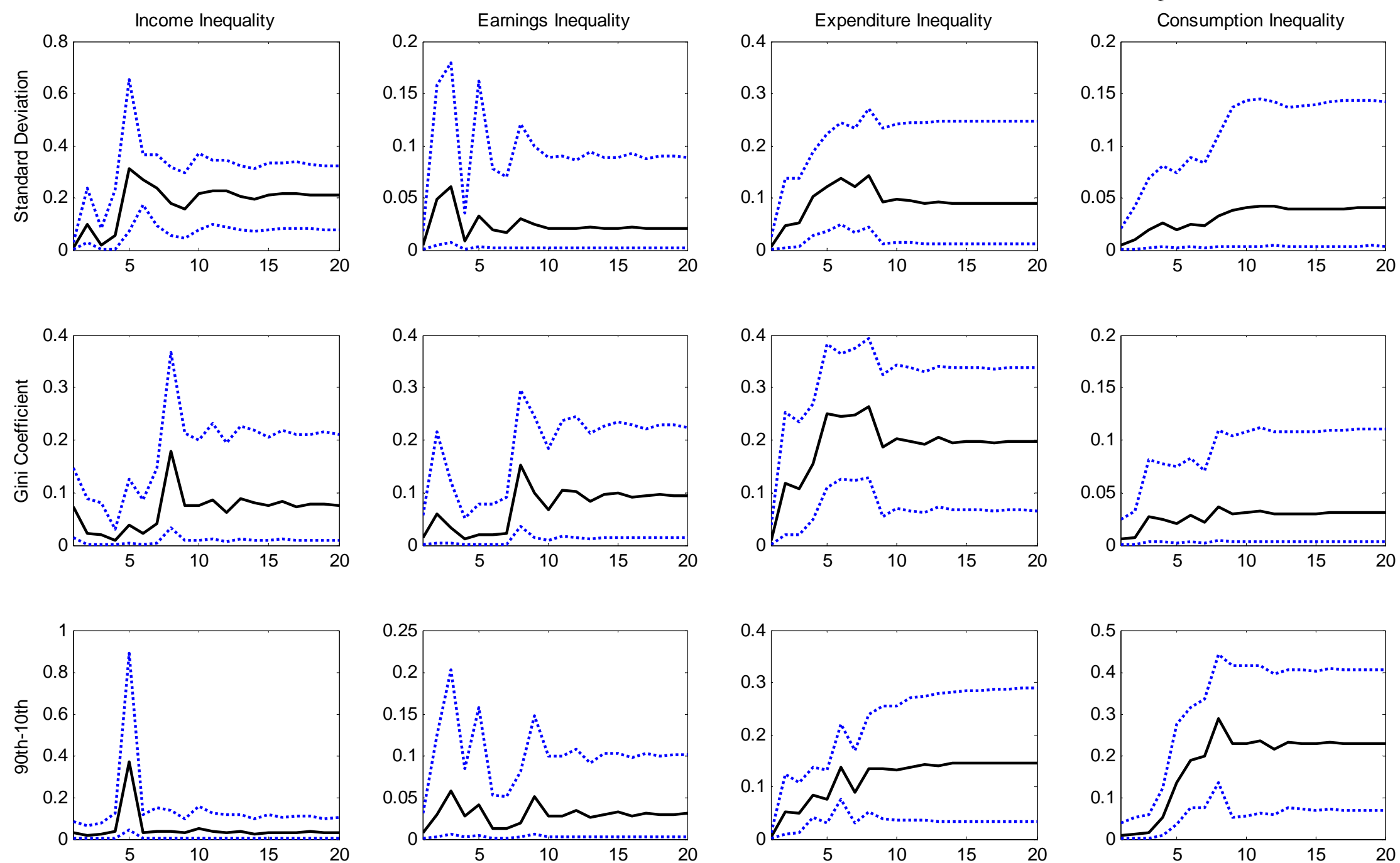

Note: The figure plots the contribution of monetary policy shocks to the forecast error variance of economic inequality at different time horizons (quarterly, $\mathrm{x}$ axis). Dotted blue lines indicate $68 \%$ confidence intervals while the solid line is the median estimate. See section 3.5 in the text for details. 
FIGURE 8: THE CONTRIBUTION OF MONETARY POLICY SHOCKS TO HISTORICAL VARIATION IN U.S. INEQUALITY

Income Inequality

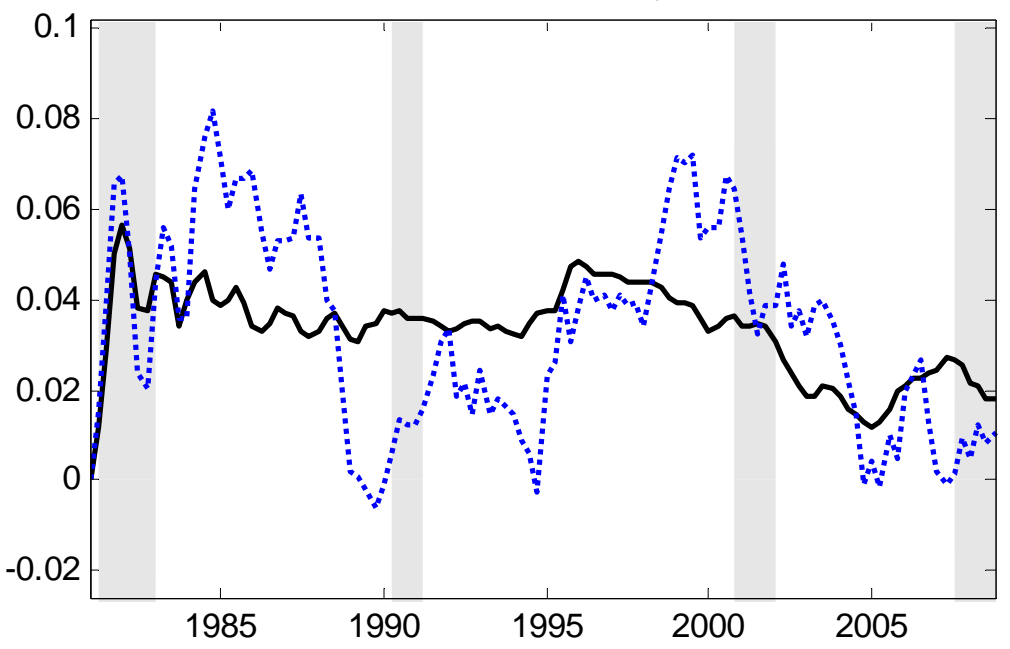

Recessions

Expenditure Inequality

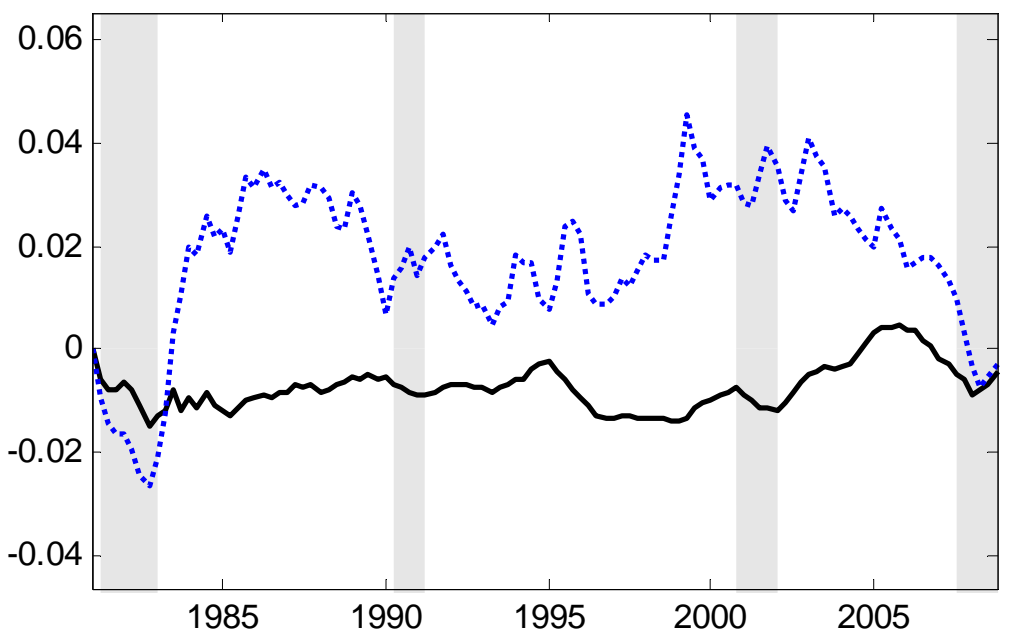

Earnings Inequality

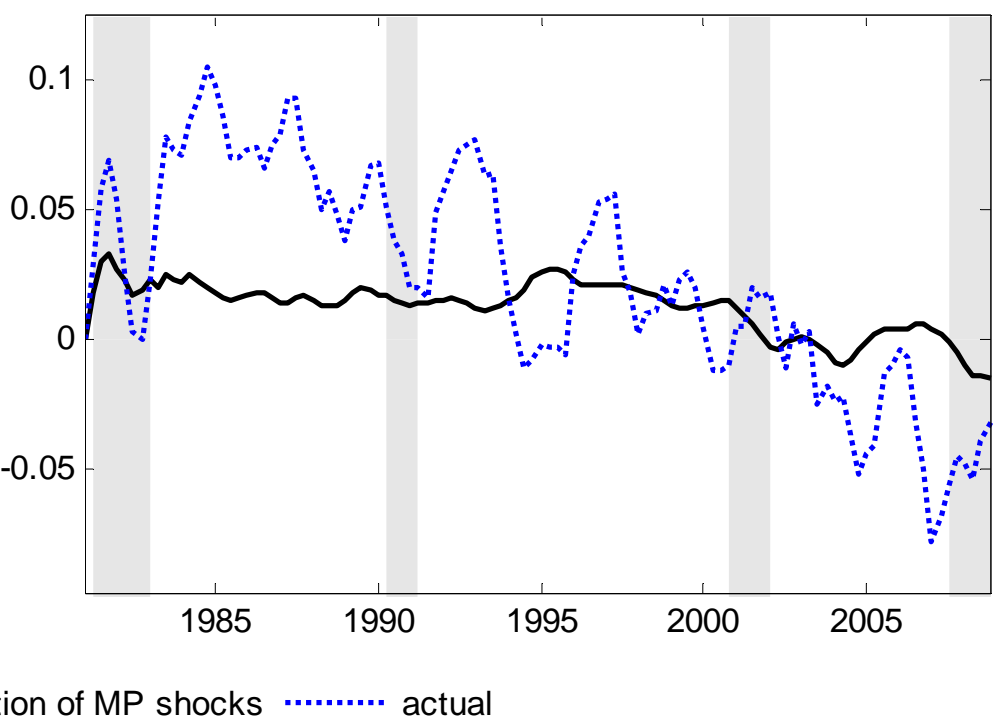

Consumption Inequality

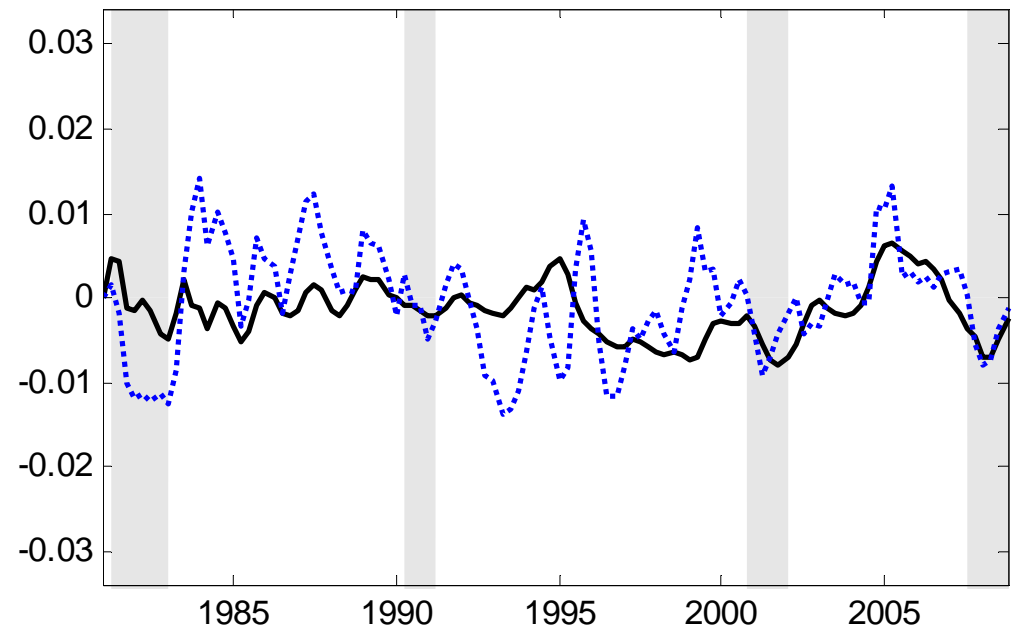

Notes: The figure plots the predicted path of different forms of U.S. inequality due only to monetary policy shocks (solid lines) versus the actual path of inequality measures (dotted lines). Inequality is measured using the cross-sectional standard deviation. Note that both actual and predicted series are normalized by the trend growth of each inequality series and are averaged over previous and subsequent quarter values. See section 3.5 for details. 
FIGURE 9: INCOME AND CONSUMPTION RESPONSES OF HIGH AND LOW NET-WORTH HOUSEHOLDS Income
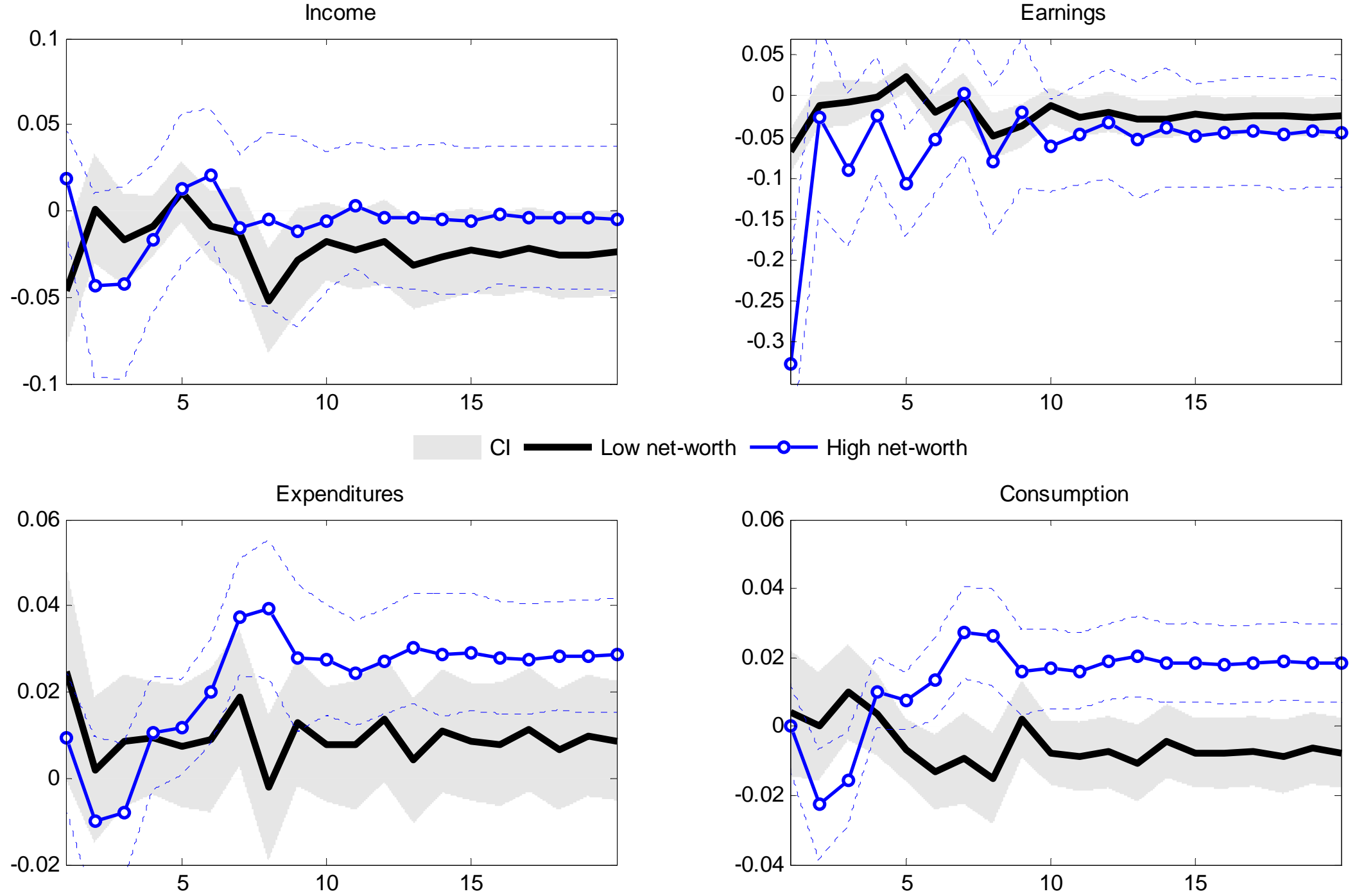

Notes: The figures plot the impulse responses of mean measures for two groups of households to a 1 percentage point (100 b.p.) contractionary monetary policy shock: low net-worth households (solid line with grey shaded area for one standard deviation confidence interval) and high net-worth households (solid line with circles and dashed lines for confidence interval). Definitions of low and high net-worth households are in section 4 in the text. 
FIGURE 10: HistORICAL ESTIMATES OF THE FEDERAL RESERVE’s TARGET RATE OF INFLATION

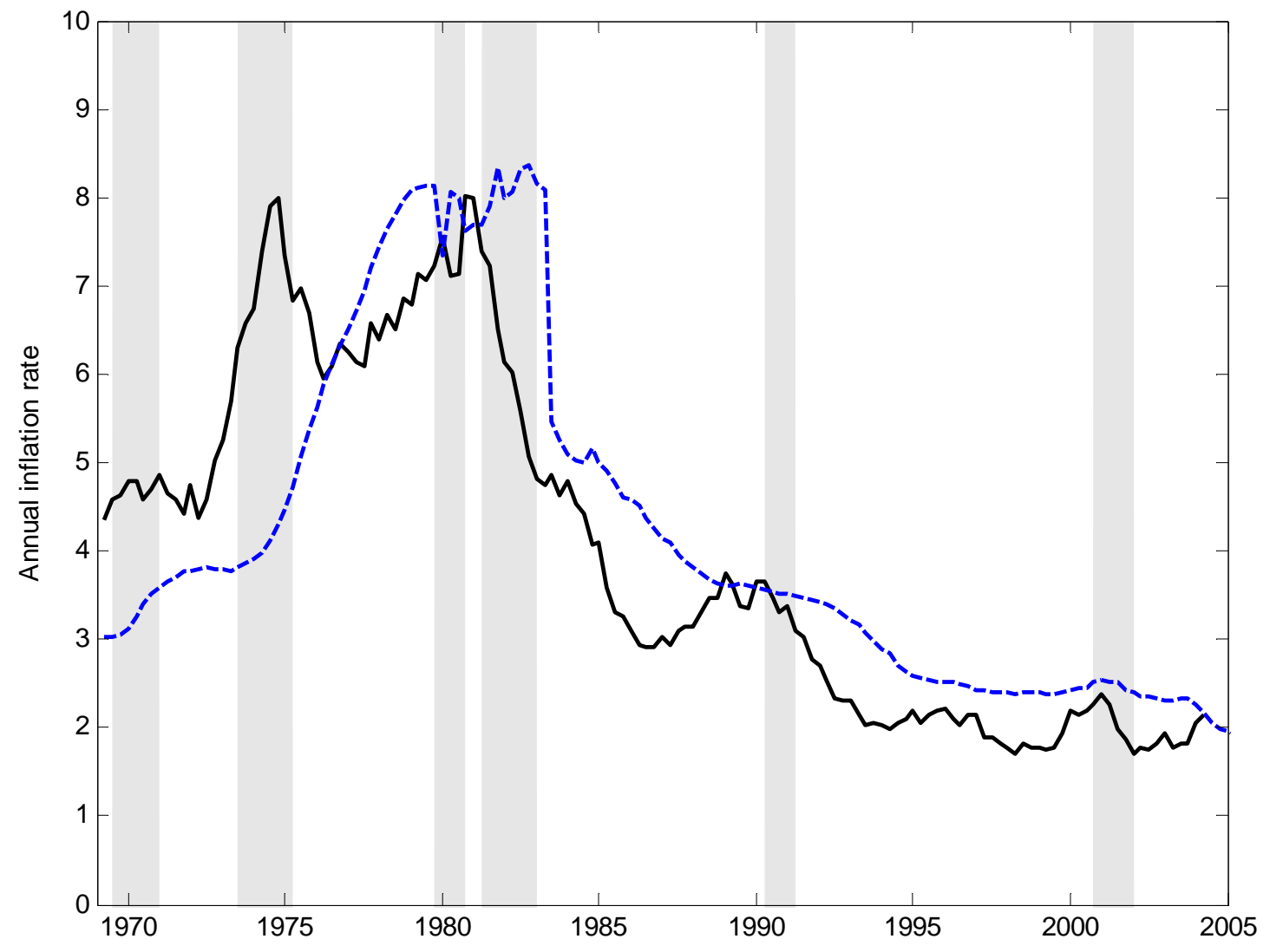

Notes: The figure plots the inflation target rate of the U.S. Federal Reserve as estimated by Ireland (2006, solid line) and Coibion and Gorodnichenko (2011, dashed line). Grey shaded areas are U.S. recessions. See section 5 for details. 
FIGURE 11: RESPONSE OF INEQUALITY TO PERMANENT INCREASES IN THE INFLATION TARGET
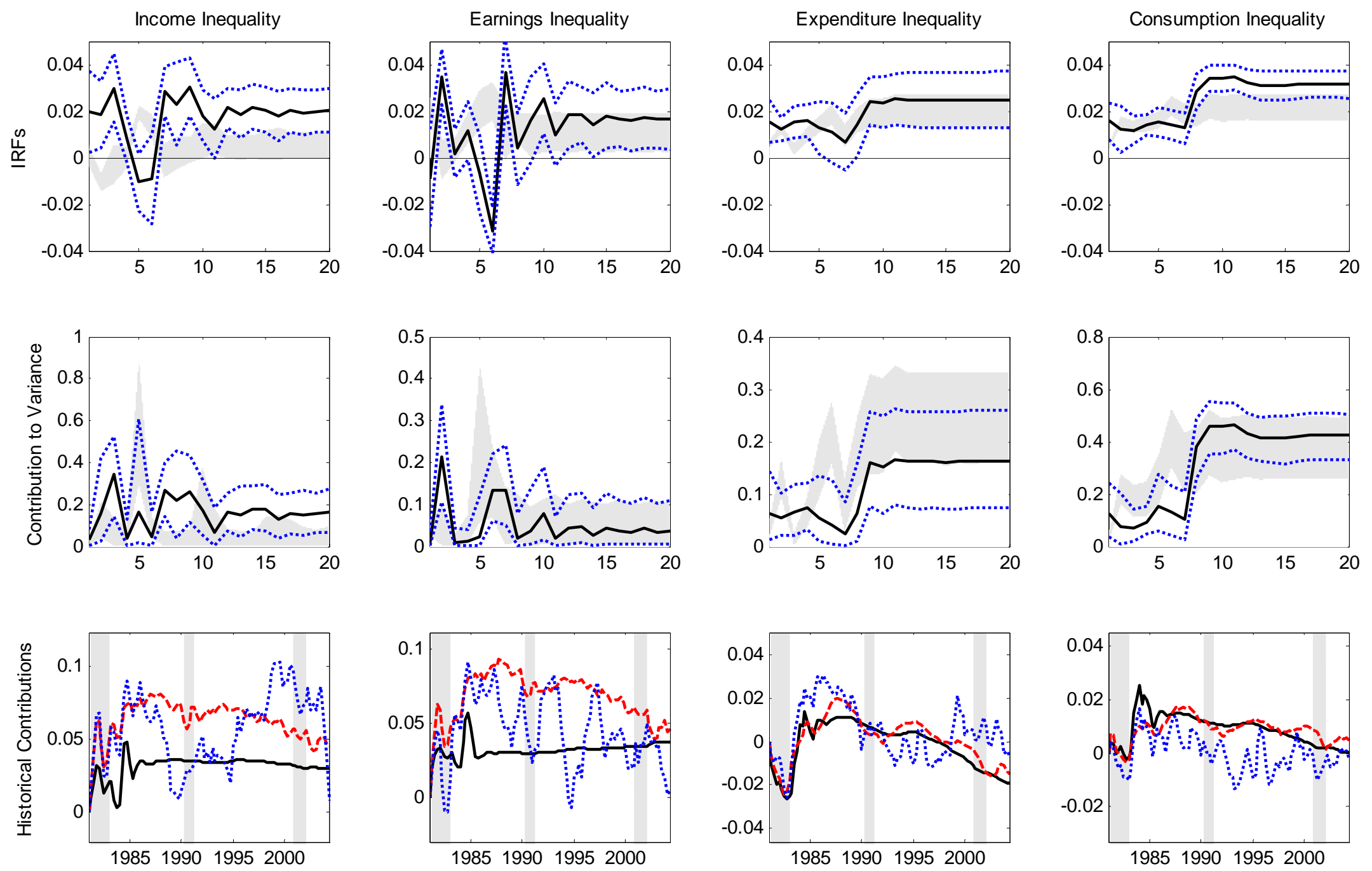

Note: The first row plots impulse responses and one standard deviation confidence intervals of the effects of a permanent $1 \%$ point decrease in the inflation target on economic inequality (measured using cross-sectional standard deviations). The second row plots the contribution of changes in inflation target to forecast error variance of inequality measures. For both the first and second row, grey shaded areas are one standard deviation confidence intervals using Coibion and Gorodnichenko (2011) measures of the inflation target. The solid line and dotted lines are point estimates and one standard deviation confidence intervals using Ireland's (2006) measure of the inflation target. The bottom row plots the historical contribution of target inflation changes to deviations of inequality from trend: dotted lines are actual historical values, solid lines are historical contributions using Coibion and Gorodnichenko (2011) inflation target measures and dashed lines are based on Ireland (2006) measures. See section 5 for details. 


\begin{tabular}{lccc}
\hline \hline Panel A: Correlations across Inequality Measures & & \\
& Corr(SD,Gini) & Corr(SD,90 $\left.-10^{\text {th }}\right)$ & Corr $\left(G i n i, 90^{\text {th }}-10^{\text {th }}\right)$ \\
\cline { 2 - 4 } Income Inequality & 0.91 & 0.93 & 0.89 \\
Earnings Inequality & 0.52 & 0.85 & 0.41 \\
Expenditures Inequality & 0.89 & 0.89 & 0.75 \\
Consumption Inequality & 0.63 & 0.80 & 0.45 \\
\hline Panel B: Correlations of Inequality in Income, Salary, Expenditures and Consumption \\
& SD & Gini & $90^{\text {th }}-10^{\text {th }}$ \\
\cline { 2 - 4 } Corr(Income, Earnings) & 0.22 & 0.82 & 0.12 \\
Corr(Income, Expenditures) & 0.32 & 0.50 & 0.23 \\
Corr(Income, Consumption) & 0.14 & 0.67 & 0.03 \\
Corr(Earnings, Expenditures) & 0.26 & 0.55 & 0.23 \\
Corr(Earnings, Consumption) & -0.05 & 0.61 & 0.00 \\
Corr(Expenditures, Consumption) & 0.59 & 0.80 & 0.42 \\
\hline Panel C: Volatility of Inequality Measures & & 0.01 & 0.03 \\
\hline Consumption Inequality & SD & 0.02 & 0.13 \\
Encome Inequality & 0.05 & Gini & $90^{\text {th }}-10^{\text {th }}$ \\
\hline Earning Inequality & 0.04 & 0.02 & 0.10 \\
\hline
\end{tabular}

Notes: Panel A presents correlation coefficients of inequality in income, earnings, expenditures, and consumption across the different measures of each: SD denotes cross-sectional standard deviation, Gini denotes Gini coefficients, and $90^{\text {th }}-10^{\text {th }}$ denotes the difference between the $90^{\text {th }}$ and $10^{\text {th }}$ percentiles of the cross-sectional distribution. Panel B presents correlation coefficients between each pair of income, earnings, expenditures, and consumption inequality for each approach (SD, Gini or $90^{\text {th }}-10^{\text {th }}$ ) to measuring inequality. Panel C presents standard deviations of each measure of inequality. All data is from 1980Q1 to 2008Q4. 


\begin{tabular}{|c|c|c|c|}
\hline \multicolumn{4}{|c|}{ Panel A: Correlation with the Quarterly Inflation Rate } \\
\hline & $\operatorname{Corr}(\pi, \mathrm{SD})$ & $\operatorname{Corr}(\pi$, Gini $)$ & $\operatorname{Corr}\left(\pi, 90^{\text {th }}-10^{\text {th }}\right)$ \\
\hline Income Inequality & -0.12 & 0.02 & -0.05 \\
\hline Earnings Inequality & -0.07 & -0.16 & -0.11 \\
\hline Expenditures Inequality & -0.05 & -0.09 & -0.04 \\
\hline Consumption Inequality & 0.06 & 0.03 & 0.03 \\
\hline \multicolumn{4}{|c|}{ Panel B: Correlation with the Unemployment Rate } \\
\hline & Corr(UE,SD) & Corr(UE,Gini) & Corr $\left(\mathrm{UE}, 90^{\text {th }}-10^{\text {th }}\right)$ \\
\hline Income Inequality & 0.01 & -0.10 & -0.02 \\
\hline Earnings Inequality & 0.00 & 0.07 & 0.08 \\
\hline Expenditures Inequality & -0.32 & -0.25 & -0.22 \\
\hline Consumption Inequality & -0.25 & -0.25 & -0.26 \\
\hline \multicolumn{4}{|c|}{ Panel C: Correlation with the Federal Funds Rate } \\
\hline & Corr(FFR,SD) & Corr(FFR,Gini) & $\operatorname{Corr}\left(\mathrm{FFR}, 90^{\text {th }}-10^{\text {th }}\right)$ \\
\hline Income Inequality & -0.12 & -0.09 & -0.08 \\
\hline Earnings Inequality & -0.08 & -0.19 & -0.19 \\
\hline Expenditures Inequality & 0.00 & -0.02 & -0.05 \\
\hline Consumption Inequality & 0.11 & 0.09 & 0.11 \\
\hline
\end{tabular}

Notes: The table presents correlations of income, labor earnings, expenditures and consumption inequality measures with the quarterly chained GDP Deflator inflation rate ( $\pi$, Panel A), unemployment rate (UE, Panel B), and the Effective Federal Funds Rate (FFR, Panel C). Correlations are done with respect to inequality measured using the cross-sectional standard deviations (first column), the Gini coefficient (second column), and the difference between the $90^{\text {th }}$ and $10^{\text {th }}$ percentiles of the cross-sectional distribution (third column). All series are HP-filtered prior to measuring correlations. The measures of unemployment and the Federal Funds rate are averages over each quarter. All data is from 1980Q1 to 2008Q4. 
TABle 3: DeComposition of INCOME By QuiNTILE

\begin{tabular}{|c|c|c|c|c|c|}
\hline \multirow{3}{*}{$\begin{array}{c}\text { Quintiles by } \\
\text { consumption of } \\
\text { nondurables and } \\
\text { services }\end{array}$} & \multicolumn{4}{|c|}{ Share of income source } & \multirow{3}{*}{$\begin{array}{l}\text { Ratio of mean consumption of } \\
\text { nondurables and services to } \\
\text { mean consumption of } \\
\text { nondurables and services in the } \\
3^{\text {rd }} \text { quintile } \\
\text { (5) }\end{array}$} \\
\hline & $\begin{array}{c}\text { Labor } \\
\text { Earnings }\end{array}$ & Business & Financial & Other & \\
\hline & $(1)$ & (2) & (3) & (4) & \\
\hline \multicolumn{6}{|c|}{ Panel A: 1980s } \\
\hline 1 & 0.352 & 0.022 & 0.112 & 0.515 & 0.42 \\
\hline 2 & 0.588 & 0.040 & 0.112 & 0.260 & 0.73 \\
\hline 3 & 0.694 & 0.057 & 0.096 & 0.153 & 1.00 \\
\hline 4 & 0.762 & 0.059 & 0.081 & 0.098 & 1.34 \\
\hline 5 & 0.767 & 0.088 & 0.078 & 0.067 & 2.18 \\
\hline \multicolumn{6}{|c|}{ Panel B: 1990s } \\
\hline 1 & 0.380 & 0.020 & 0.106 & 0.494 & 0.43 \\
\hline 2 & 0.597 & 0.040 & 0.097 & 0.267 & 0.73 \\
\hline 3 & 0.704 & 0.050 & 0.086 & 0.160 & 1.00 \\
\hline 4 & 0.770 & 0.056 & 0.071 & 0.103 & 1.35 \\
\hline 5 & 0.773 & 0.082 & 0.076 & 0.069 & 2.27 \\
\hline \multicolumn{6}{|c|}{ Panel C: 2000s } \\
\hline 1 & 0.435 & 0.019 & 0.086 & 0.460 & 0.43 \\
\hline 2 & 0.653 & 0.029 & 0.085 & 0.234 & 0.73 \\
\hline 3 & 0.740 & 0.037 & 0.072 & 0.151 & 1.00 \\
\hline 4 & 0.801 & 0.042 & 0.065 & 0.092 & 1.36 \\
\hline 5 & 0.812 & 0.051 & 0.071 & 0.065 & 2.32 \\
\hline
\end{tabular}

Notes: The table presents a decomposition of sources of household income in the CEX by quintile. Households are sorted into quintiles using their consumption levels of nondurables and services. Income categories include labor earnings, business income, financial income, and other sources of income. See section 3.3 in the text for details. 
TABLE 4: DECOMPOSITION OF EXPENDITURES AND CONSUMPTION BY QUINTILE

\begin{tabular}{|c|c|c|c|c|c|c|c|}
\hline \multirow{3}{*}{$\begin{array}{l}\text { Quintiles by } \\
\text { consumption of } \\
\text { nondurables } \\
\text { and services }\end{array}$} & \multicolumn{3}{|c|}{ Shares in consumption } & \multicolumn{3}{|c|}{ Selected shares in total spending } & \multirow{2}{*}{$\begin{array}{l}\text { Ratio of total } \\
\text { spending to } \\
\text { consumption } \\
\text { of nondurables } \\
\text { and services }\end{array}$} \\
\hline & Nondurables & Durables & Services & $\begin{array}{c}\text { Interest } \\
\text { sensitive } \\
\text { expenditures }\end{array}$ & $\begin{array}{l}\text { Mortgage } \\
\text { payments }\end{array}$ & $\begin{array}{l}\text { Purchases of } \\
\text { new vehicles }\end{array}$ & \\
\hline & $(1)$ & $(2)$ & (3) & $(4)$ & $(5)$ & (6) & $(7)$ \\
\hline \multicolumn{8}{|c|}{ Panel A: 1980s } \\
\hline 1 & 0.697 & 0.054 & 0.249 & 0.098 & 0.015 & 0.014 & 1.84 \\
\hline 2 & 0.681 & 0.081 & 0.237 & 0.163 & 0.040 & 0.032 & 1.85 \\
\hline 3 & 0.665 & 0.098 & 0.237 & 0.196 & 0.060 & 0.038 & 1.84 \\
\hline 4 & 0.651 & 0.106 & 0.244 & 0.235 & 0.081 & 0.047 & 1.85 \\
\hline 5 & 0.611 & 0.114 & 0.275 & 0.260 & 0.085 & 0.058 & 1.83 \\
\hline \multicolumn{8}{|c|}{ Panel B: 1990s } \\
\hline 1 & 0.655 & 0.059 & 0.285 & 0.113 & 0.021 & 0.015 & 2.13 \\
\hline 2 & 0.637 & 0.084 & 0.279 & 0.175 & 0.050 & 0.034 & 2.08 \\
\hline 3 & 0.631 & 0.096 & 0.273 & 0.215 & 0.074 & 0.040 & 2.03 \\
\hline 4 & 0.613 & 0.109 & 0.278 & 0.246 & 0.094 & 0.046 & 2.02 \\
\hline 5 & 0.567 & 0.116 & 0.317 & 0.267 & 0.100 & 0.051 & 1.91 \\
\hline \multicolumn{8}{|c|}{ Panel C: 2000s } \\
\hline 1 & 0.630 & 0.057 & 0.313 & 0.120 & 0.033 & 0.014 & 2.23 \\
\hline 2 & 0.620 & 0.073 & 0.307 & 0.182 & 0.070 & 0.029 & 2.12 \\
\hline 3 & 0.613 & 0.087 & 0.299 & 0.217 & 0.089 & 0.037 & 2.12 \\
\hline 4 & 0.599 & 0.098 & 0.303 & 0.256 & 0.106 & 0.046 & 2.10 \\
\hline 5 & 0.541 & 0.109 & 0.351 & 0.278 & 0.110 & 0.051 & 1.99 \\
\hline
\end{tabular}

Note: The table presents a decomposition of consumption and expenditures in the CEX by quintile. Households are sorted into quintiles using their consumption levels of nondurables and services. Consumption includes nondurables, services and durables. Total spending is the sum of consumption and other expenditures, including auto purchases, mortgage payments among others. See section 3.3 in the text for details. 
APPENDIX FIGURE 1: ROBUSTNESS OF BASELINE INEQUALITY RESULTS TO SAMPLE AND LAGS
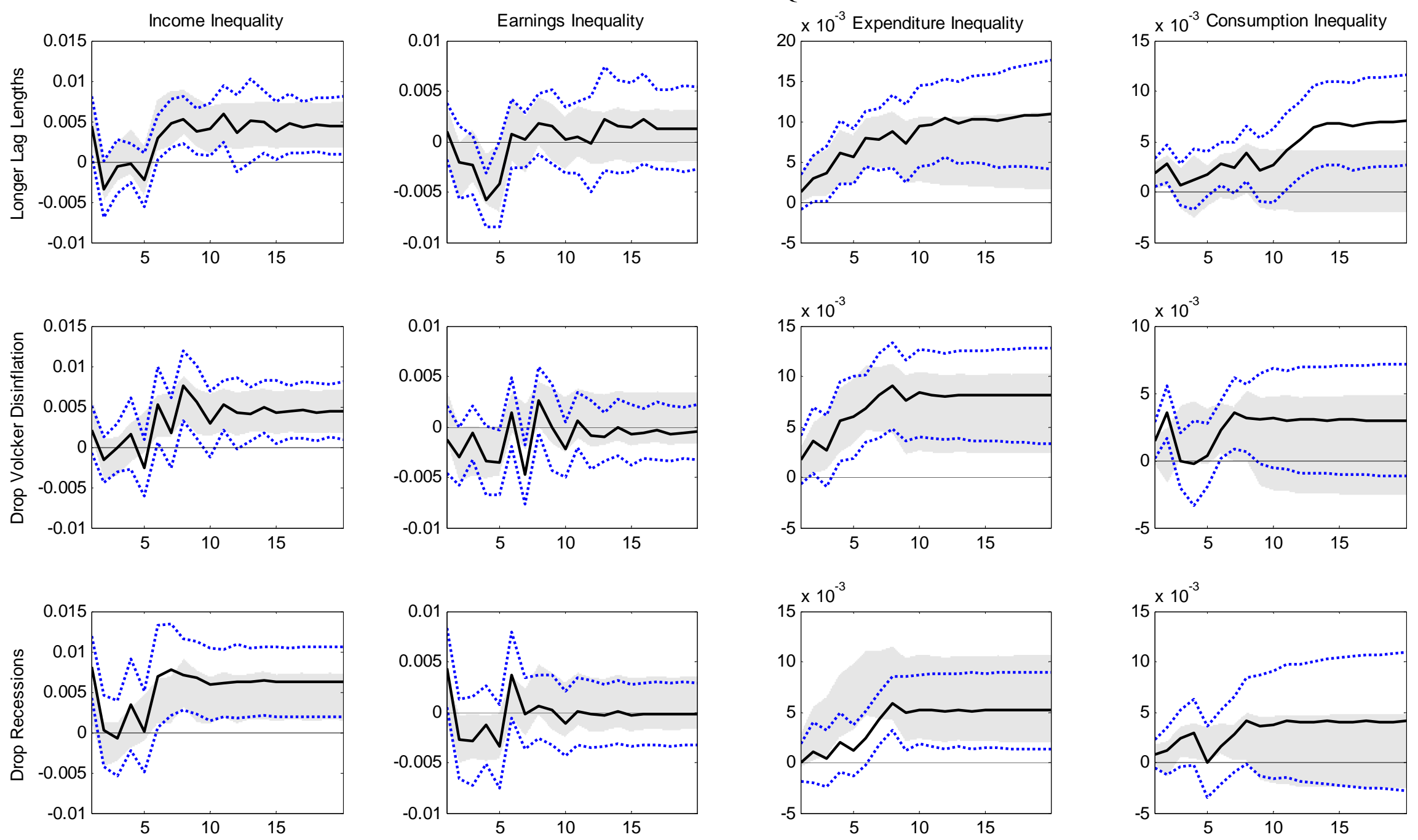

Notes: The figure plots impulse responses of inequality measures (Gini coefficients) for total income (first column), salary income (second column), total expenditures (third column), and consumption (fourth column) in response to a 1 percentage point (100 b.p.) contractionary monetary policy shock. Grey shaded areas are one-standard deviation confidence intervals from the baseline specification while dotted lines represent one-standard deviation intervals with longer lags (row 1), starting in 1985Q1 (row 2), or dropping all recession quarters (row 3). See section 3.2 for details. 
APPENDIX FIGURE 2: ROBUSTNESS OF BASELINE INEQUALITY RESULTS TO ECONOMETRIC APPROACH
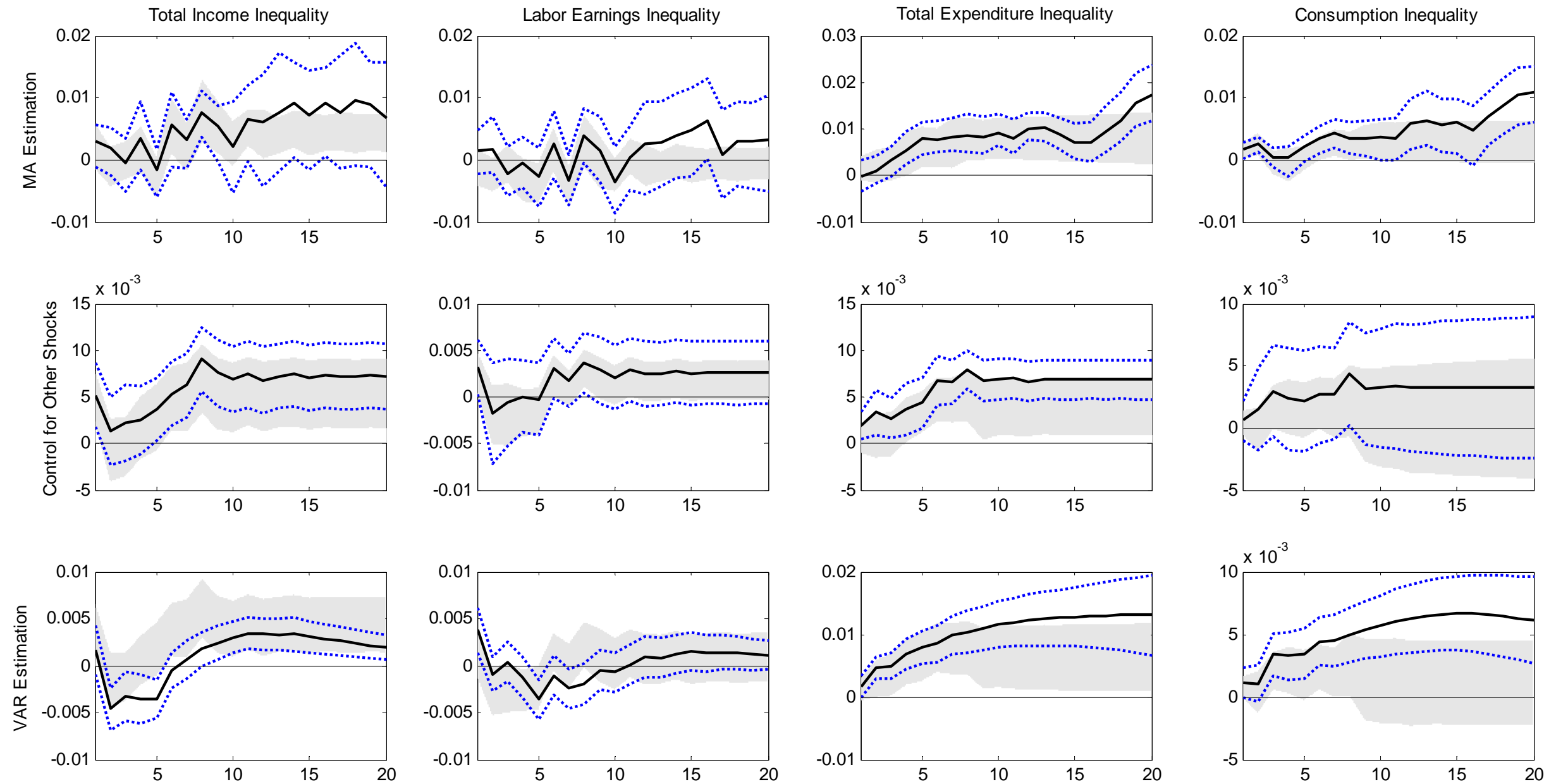

Notes: The figure plots impulse responses of inequality measures (Gini coefficients) for total income (first column), salary income (second column), total expenditures (third column), and consumption (fourth column) in response to a 1 percentage point (100 b.p.) contractionary monetary policy shock. Grey shaded areas are one-standard deviation confidence intervals from the baseline specification while dotted lines represent one-standard deviation intervals from movingaverage representation estimation (row 1), controlling for other shocks (row 2), or VAR estimation (row 3). See section 3.2 for details. 


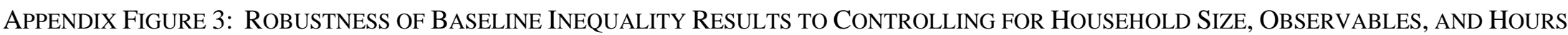
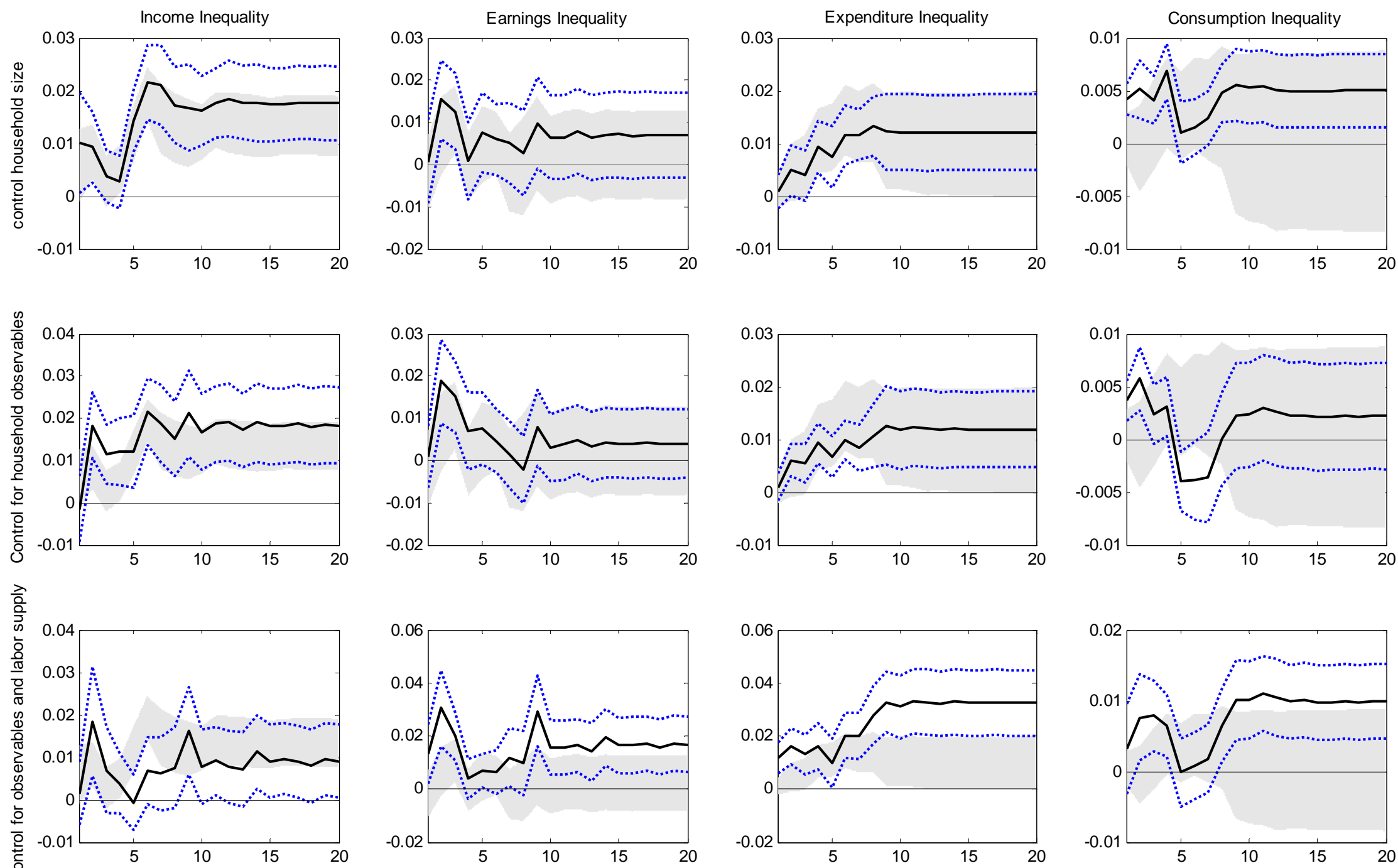

Notes: The figure plots impulse responses of inequality measures (cross-sectional standard deviations) for total income (first column), salary income (second column), total expenditures (third column), and consumption (fourth column) in response to a 1 percentage point (100 b.p.) contractionary monetary policy shock. Grey shaded areas are one-standard deviation confidence intervals from the baseline specification while dotted lines represent one-standard deviation intervals when controlling for household size (row 1), controlling for all household observables (row 2), or controlling for household observables and labor supply (row 3). See section 3.2 for details. 


\section{APPENDIX FIgURE 4: ROBUSTNESS OF EARNINGS RESPONSES BY PERCENTILES}
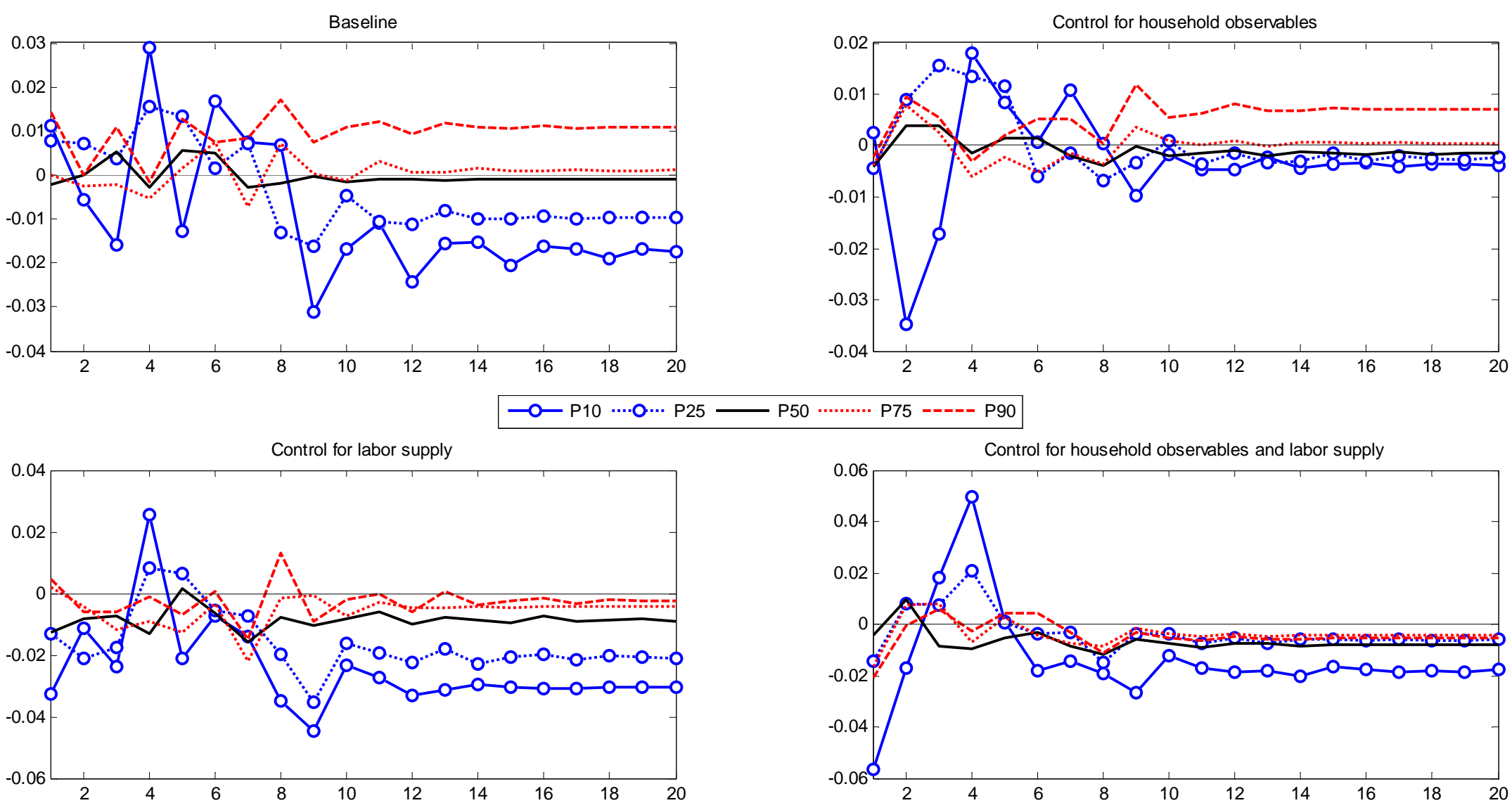

Notes: The figures plot the responses of labor earnings at different percentiles of the earnings distribution (P10: $10^{\text {th }}$ and lowest percentile, P50 and P90). The top left figure reproduces our baseline estimates. The top right panel controls for household observables in measuring household earnings. The bottom left panel controls for hours worked. The bottom right panel controls for household observables and hours worked. See section 3.4 for details. 


\section{APPENDIX FIGURE 5: CONTRIBUTION OF MONETARY POLICY SHOCKS TO VARIANCE OF MACROECONOMIC VARIABLES}
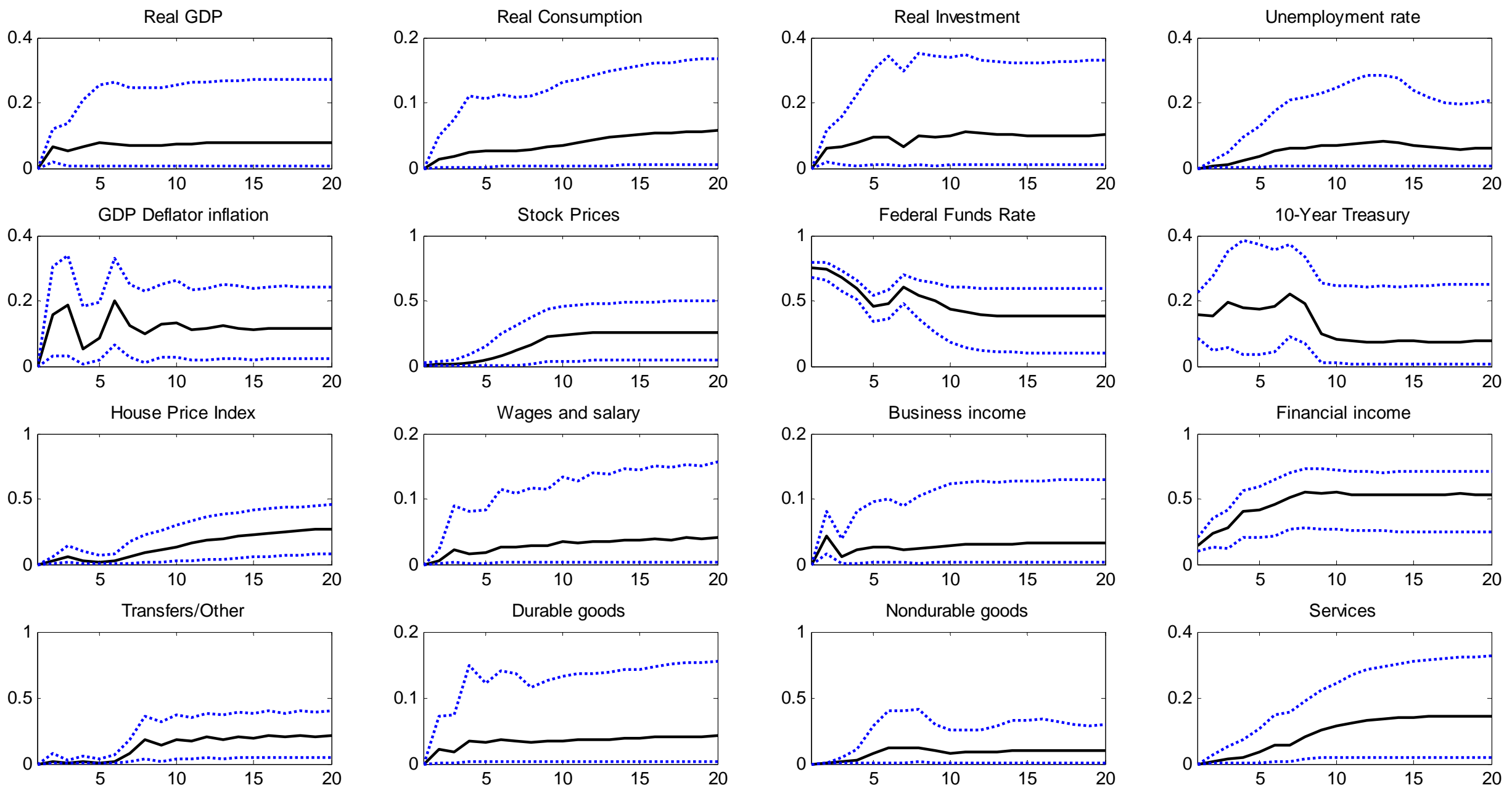

Notes: The figure presents the contribution of monetary policy shocks to the variance of each macroeconomic variable at different horizons (quarterly, $\mathrm{x}$-axis) from estimates of equation (2) in the text using data from 1980Q1 to 2008Q4. The solid line is the median estimate and the dotted lines are the one standarddeviation confidence intervals from the distribution of estimated parameters in equation (2) for each variable. See section 3.5 for details. 
APPENDIX FIgURE 6: Distributional EFFECTS By PERCENTILE OF INFLATION TARgET INCREASES
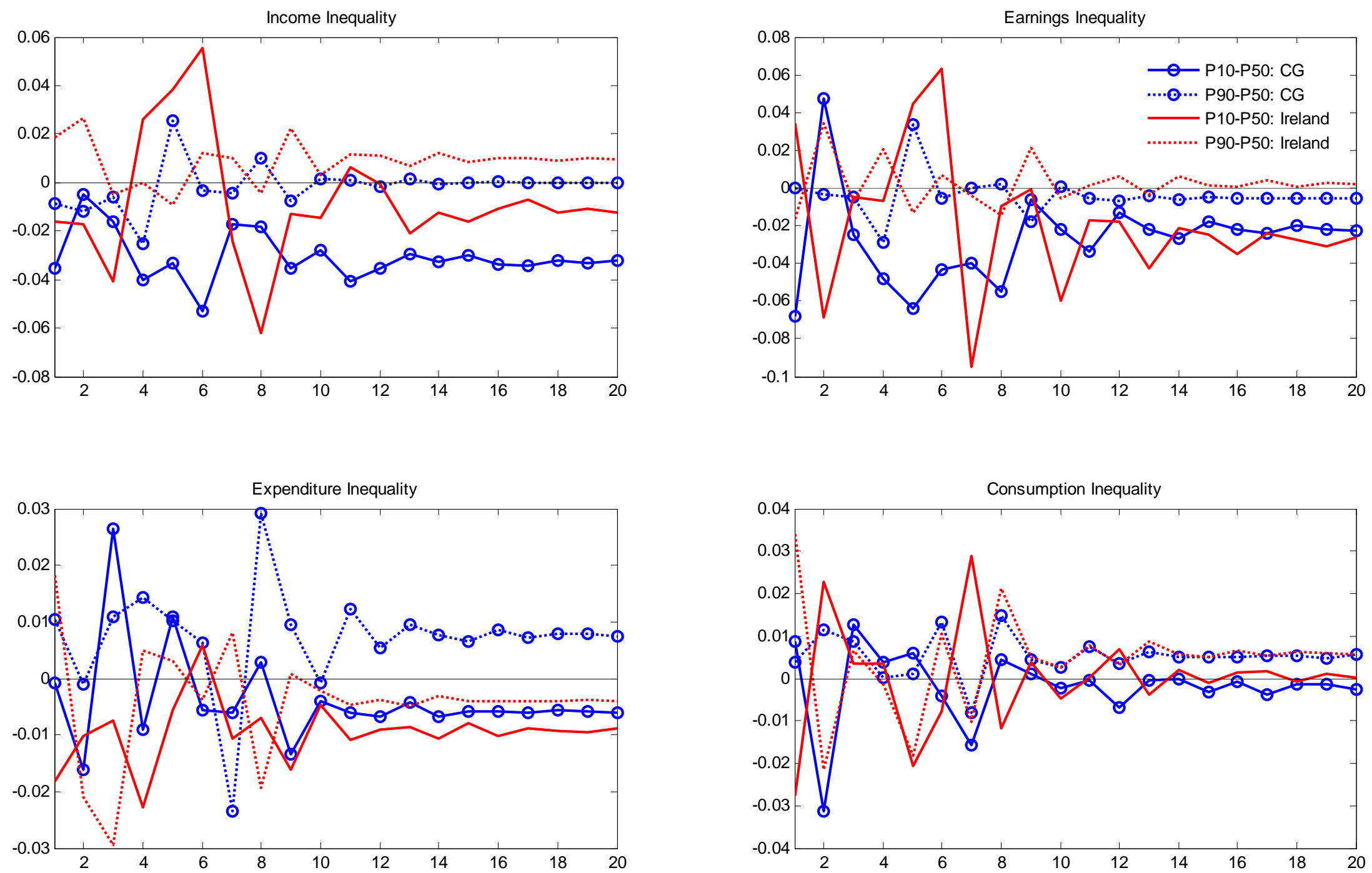

Notes: Figures plot impulse responses of different percentile differentials (e.g. P90-P50: difference between the $90^{\text {th }}$ percentile and the $50^{\text {th }}$ percentile) of the income distribution (top-left), labor earnings distribution (top-right), total expenditure distribution (bottom-left) and consumption distribution (bottom-right) in responses to a $1 \%$ point increase in the target inflation rate as measured by Coibion and Gorodnichenko (2011, lines with circles) or Ireland (2006, lines without circles). See section 5 for details. 